Research Article

\title{
Strengthening of RCC Beams in Shear by Using SBR Polymer-Modified Ferrocement Jacketing Technique
}

\author{
Rajinder Ghai (D), Prem Pal Bansal, and Maneek Kumar (iD \\ Department of Civil Engineering, Thapar University, Patiala, Punjab 147004, India \\ Correspondence should be addressed to Rajinder Ghai; ghairajinder@gmail.com
}

Received 24 August 2017; Accepted 21 November 2017; Published 13 February 2018

Academic Editor: Lucia Figuli

Copyright (C) 2018 Rajinder Ghai et al. This is an open access article distributed under the Creative Commons Attribution License, which permits unrestricted use, distribution, and reproduction in any medium, provided the original work is properly cited.

There is a common phenomenon of shear failure in RCC beams, especially in old buildings and bridges. Any possible strengthening of such beams is needed to be explored that could strengthen and make them fit for serviceable conditions. The present research has been made to determine the performance of predamaged beams strengthened with three-layered wire mesh polymer-modified ferrocement (PMF) with 15\% styrene-butadiene-rubber latex (SBR) polymer. Forty-eight shear-designed and shear-deficient real-size beams were used in this experimental work. Ultimate shear load-carrying capacity of control beams was found at two different shear-span $(a / d)$ ratios 1 and 3 . The sets of remaining beams were loaded with different predetermined damage levels of $45 \%, 75 \%$, and $95 \%$ of the ultimate load values and then strengthened with $20 \mathrm{~mm}$ thick PMF. The strengthened beams were then again tested for ultimate load-carrying capacity by conducting the shear load test at $a / d=1$ and 3 . As a result, the PMF-strengthened beams showed restoration and enhancement of ultimate shear load-carrying capacity by $5.90 \%$ to $12.03 \%$. The ductility of strengthened beams was improved, and hence, the corresponding deflections were prolonged. On the other hand, the cracking pattern of PMF-strengthened beams was also improved remarkably.

\section{Introduction}

With the passage of time, many of the existing RCC structures deteriorate due to increases in service loads, corrosion of reinforcement, and poor ductile detailing, which results in loss of strength, cracking, and spalling of the structural components. Such structural elements need special attention and must be retrofitted using suitable strengthening techniques to restore strength and the design life. Many researchers have worked on the development of various materials and techniques for repairing, retrofitting, and strengthening of such structural elements. The selection of a particular strengthening material and technique depends on the type, cause, and nature of distress to be addressed.

All RCC elements are designed to fail in a ductile manner by making suitable detailing of reinforcement. During an earthquake, a sudden catastrophic failure can occur due to increased shear loads [1]. In reinforced concrete beams, the shear deficiencies pop up due to many reasons such as insufficient shear reinforcement, reduction in the steel area, increasing service loads, poor workmanship, and design faults. Shear strength of many existing structures might be deficient for present needs and requires strengthening to sustain and to satisfy current codal requirements. The engineers have experienced that shear failure of RCC beams, especially in older or heritage structures, buildings, and bridges, is a serious problem which necessitates dismantling and replacement of the structures. Hence, there is a need of developing an economical strengthening solution, which helps to restore the desired shear strength of beams.

In the recent years, the usage of different advanced materials such as ferrocement, glass fibre-reinforced polymer (GFRP), fibre-reinforced polymer (FRP), carbon fibre-reinforced polymer (CFRP), and steel plate jacketing has increased for retrofitting and strengthening of concrete structures. These materials have excellent properties such as high strength, light weight, and corrosion resistance abilities. Some researchers have explored the effect of various advanced composite bonding materials as 
well as their orientation on the flexure and shear strength properties of retrofitted beams [2-15]. Many of these materials showed some flaws or shortcomings in terms of strength, cost, availability, and applicability. Hence, out of these available material options, the ferrocement has gained popularity and becomes the major structural material for strengthening and retrofitting as well for construction, especially in earthquake-prone areas because of its excellent ductility, toughness, availability, and other properties. Researchers have come to the conclusion that ferrocement is quite compatible with the existing concrete structures; apart from this, it is easy to apply [16-23].

Conventional ferrocement made with cement mortar matrix showed some deficiencies and got cracks under loads even much smaller than the ultimate loads, leading to reduced life [24-27]. The corrosion of wire mesh is also one of the primary reasons for the deterioration of ferrocement which is attributed to the permeability of cement mortar $[28,29]$. To overcome these deficiencies of conventional ferrocement; it is necessary to enhance the properties of its mortar matrix with different types of additives. The addition of polymers to the conventional mortar is found to be very effective [30-39]. It further imparts some outstanding properties like resistance to corrosion, higher strength-to-weight ratio, better ductility, and tensile strength as compared to conventional ferrocement [40-44]. There are various types of polymers available worldwide, but the studies have shown that the addition of styrenebutadiene-rubber latex (SBR) polymer is very efficient in improving the properties of conventional mortar and ferrocement [45-49]. Polymer-modified ferrocement is gaining popularity in developing countries because of its excellent properties and as an economical repair alternative to the expensive process of reconstruction. Details of PMF are simple to follow and easy to execute even by local skilled workers and the ingredients being readily available [5054]. Further developments in the field of polymer-modified ferrocement (PMF) can make a drastic improvement in the area of composite rehabilitation and strengthening of existing structures.

In the past, a few experimental studies had been carried out to gauge the effect of the high-performance ferrocement strengthening technique on RCC beams. Kumar and Vidivelli $[50,51]$ investigated the use of acrylic latex and styrene-butadiene-rubber latex polymer-modified ferrocement to strengthen the RCC beams in flexure. Their test results showed that the strengthened beams exhibited $79 \%$ to $85 \%$ enhancement in their general performance after the usage of polymer ferrocement jacketing, having $15 \%$ of polymer and 5\% volume of wire mesh. A similar study was made by Liao and Fang [52], and they found that RC beams strengthened with high-performance ferrocement showed higher ultimate load-carrying capacities and minor cracks as compared to controlled beams. Hughes and Evbuomwan [53] also used the polymer-modified ferrocement under the soffit of beams to strengthen the beams in flexure. They resulted that the ductility and ultimate flexural load-carrying capacity of beams were increased after strengthening, without any bond failure. Zhao et al. [54] used the polymer mortar and steel wire to strengthen the beams in shear. These strengthened beams showed the delay in crack development and improvement in the ultimate load capacity by $57 \%$ as compared to controlled beams. They also concluded that polymer mortar showed good bonding properties with the concrete members.

It is concluded that the application of polymermodified ferrocement as an outer strengthening material is a viable technology for improving the structural performance of RCC beams in flexure. At present, there is no such research work recorded to study the effects of polymer-modified ferrocement to strengthen the beams in shear. It is the need of the hour to explore the utility of $\mathrm{PMF}$ as a strengthening material in the specified domain of shear. Many factors impart shear strength of RCC beams like a/d ratio, spacing of stirrups, and grade of concrete. In this experimental work, two variable factors as a/d ratio and spacing of stirrups are chosen to find their effect on strength, deflection, and cracking pattern of predamaged beams strengthened with PMF. Another study done by the authors showed that the PMF modified with $15 \%$ of SBR and three layers of square woven steel wire mesh had better flexural and tensile strength properties as compared to other compositions [45]. Therefore, three-layered wire mesh polymer-modified ferrocement with an optimum percentage of $15 \%$ SBR has been used in this experimental work to strengthen the RCC beams having three different levels of predamages.

\section{Materials and Methods}

A preliminary study has been done to determine the properties of ingredients required for this experimental work.

2.1. Materials. Portland pozzolana cement (PPC) with a 28 day compressive strength of $34.2 \mathrm{~N} / \mathrm{mm}^{2}$, specific gravity 2.9 , fineness $2.1 \%$, consistency $34 \%$, initial setting time 98 minutes, final setting time 240 minutes, and soundness of $1 \mathrm{~mm}$ conforming to IS 1489-Part 1 [55] was used in the mortar and concrete. Natural sand (FA-1) was used to prepare the mortar mix for ferrocement, and riverbed sand (FA-2) was used for concrete mix, as per IS 383 [56] specifications. Two types of coarse aggregates with nominal size of $20 \mathrm{~mm}$ and $12.5 \mathrm{~mm}$ in a ratio of $60: 40$ were used to prepare the concrete mix as per IS 2386-Part 3 [57] specifications. Detail of test results of fine and coarse aggregates is given in Table 1.

The thermomechanical-treated (TMT) $12 \mathrm{~mm}$ diameter bars with an ultimate tensile strength of $710 \mathrm{~N} / \mathrm{mm}^{2}$ were used as tensile reinforcement, and $8 \mathrm{~mm}$ diameter TMT bars which have an ultimate tensile strength of $697.5 \mathrm{~N} / \mathrm{mm}^{2}$ were used as compressive reinforcement. Plain mild steel (MS) $6 \mathrm{~mm}$ diameter reinforcement bars with an ultimate tensile strength of $491.5 \mathrm{~N} / \mathrm{mm}^{2}$ were used as shear reinforcement. Galvanised square woven wire mesh of $0.49 \mathrm{~mm}$ diameter with centre-to-centre spacing of $8 \mathrm{~mm}$ and having an ultimate tensile strength of $950 \mathrm{~N} / \mathrm{mm}^{2}$ was 
TABle 1: Properties of fine and coarse aggregates.

\begin{tabular}{lccccc}
\hline Material description & Fineness modulus & Specific gravity & Water absorption (\%) & Moisture content (\%) & Grading zone \\
\hline Fine aggregate (FA-1) & 2.24 & 2.67 & 1.9 & 0.22 & 3 \\
Fine aggregate (FA-2) & 2.65 & 2.675 & 1.35 & 0.16 & 2 \\
Coarse aggregate (CA-1) $20 \mathrm{~mm}$ & 6.69 & 2.69 & 1.18 & Nil & All-in-aggregate \\
Coarse aggregate (CA-2) $12.5 \mathrm{~mm}$ & 6.11 & 2.685 & 1.11 & Nil & All-in-aggregate \\
\hline
\end{tabular}

used in polymer-modified ferrocement as per ACI 549.1R guidelines [58]. Details of test results are given in Table 2.

Commercially available Sika ${ }^{\circledR}$ Latex Power [59] SBRbased polymer in liquid form having $45 \%$ solid contents, $\mathrm{pH}$ value of 8.50 at $25^{\circ}$, and specific gravity of 1.01 was used to modify the current mortar matrix of ferrocement. A $0.7 \%$ silicon solid by weight of the SBR polymer was used as an antifoaming agent in the PMF matrix [60]. Potable water was used for mixing and curing purposes.

2.1.1. Concrete Mix. Concrete of grade M20 with C: FA : CA in a ratio of $1: 2.1: 3.4$ was designed as per IS 10262 [61] guidelines. The water-cement ratio of the concrete mix was 0.55 and having an ultimate compressive strength of $26.72 \mathrm{~N} / \mathrm{mm}^{2}$. The slump value of the mix was kept as $75 \mathrm{~mm}-100 \mathrm{~mm}$. This concrete mix proportion was used to cast all the beam specimens. Detail of quantities required per $\mathrm{m}^{3}$ of concrete is given in Table 3 .

2.1.2. Polymer-Modified Ferrocement (PMF). Polymermodified mortar (PMM) with a cement (C) to sand (FA-1) ratio of $1: 2$ and having $15 \%$ of SBR was used to develop the polymer-modified ferrocement (PMF). The watercement ratio of mortar was found as 0.56 for a flow value of $105 \pm 5 \%$ [62]. The 28-day compressive strength, flexural strength, and Young's modulus of elasticity of PMM were $31.53 \mathrm{~N} / \mathrm{mm}^{2}, \quad 8.52 \mathrm{~N} / \mathrm{mm}^{2}$, and $13.15 \times 10^{3} \mathrm{~N} / \mathrm{mm}^{2}$, respectively [45]. This polymer-modified mortar was further used to modify the three-layered square woven steel wire mesh ferrocement. The 28-day flexural and tensile strengths of polymer-modified ferrocement were $17.01 \mathrm{~N} / \mathrm{mm}^{2}$ and $6.12 \mathrm{~N} / \mathrm{mm}^{2}$, respectively [45]. This PMF is used as an encasing material in this experimental work to strengthen the predamaged RCC beams.

2.2. Experimental Program and Methods. This experimental study was conducted on 48 full-size $(127 \mathrm{~mm} \times 229 \mathrm{~mm}$ $\times 2700 \mathrm{~mm}$ ) RCC beams. Out of these 48 beams, 24 were designed for shear-designed beams (DBs), and 18 stirrups of $6 \mathrm{~mm}$ diameter were provided at a spacing of $150 \mathrm{~mm} \mathrm{c} / \mathrm{c}$. The rest 24 beams were designed as shear-deficient beams (SDBs), and 7 stirrups of $6 \mathrm{~mm}$ diameter were provided at a spacing of $450 \mathrm{~mm} \mathrm{c} / \mathrm{c}$. All the beams were confined with $2-12 \mathrm{~mm}$ diameter bars on tensile face and $2-8 \mathrm{~mm}$ diameter bars on compression face. Beam section and reinforcement details of both types of beams are shown in Figure 1. For casting beam specimens, the reinforcement was correctly placed in the formwork with specified cover and then poured with concrete. A steel formwork was used, and IS 456 [63] specifications were
Table 2: Properties of reinforcement steel bars.

\begin{tabular}{lccc}
\hline Diameter $(\mathrm{mm})$ & $\begin{array}{c}\text { Yield stress } \\
(\mathrm{MPa})\end{array}$ & $\begin{array}{c}\text { Ultimate stress } \\
(\mathrm{MPa})\end{array}$ & $\begin{array}{c}\text { Elongation } \\
(\%)\end{array}$ \\
\hline 12 & 556.5 & 710.0 & 22.0 \\
8 & 548.5 & 679.5 & 18.4 \\
6 & 465.0 & 491.5 & 5.0 \\
$\begin{array}{l}0.49 \text { (square woven } \\
\text { wire mesh) }\end{array}$ & 665.0 & 950.0 & 18.2 \\
\hline
\end{tabular}

TABle 3: Detail of concrete mix design.

\begin{tabular}{lccc}
\hline $\begin{array}{l}\text { Cement } \\
(\mathrm{C})\end{array}$ & $\begin{array}{c}\text { Fine aggregate } \\
(\mathrm{FA}-2)\end{array}$ & $\begin{array}{c}\text { Coarse aggregate (CA-1: } \\
\text { CA-2) }(60: 40)\end{array}$ & $\begin{array}{c}\text { Water } \\
(\mathrm{W})\end{array}$ \\
\hline 340 & 714.0 & 1156 & 187 \\
\hline
\end{tabular}

All quantities are in $\mathrm{Kg}$.

strictly followed. The detail of beams along with their designation is given in Table 4 .

2.2.1. Testing of Controlled Beams. After 28 days of curing, the shear-designed and shear-deficient controlled beams were tested over a loading frame fixed with a hydraulic jack. The load test on all the beams was performed for two different shear-span $(a / d)$ ratios 1 and 3 over a simply supported effective span of $2500 \mathrm{~mm}$ as shown in Figure 2. A standard set of 3 beams was taken for each load test. Loaddeflection curves were observed, and the ultimate shear loadcarrying capacities of controlled beams (DBs and SDBs) were worked out by applying single-point load "P" at two different shear-span ratios $(a / d)=1.0$ and 3.0, respectively, where " $a$ " denotes the shear span of the beam and " $d=198 \mathrm{~mm}$ " denotes the effective depth of the beam. For $a / d=1.0$, the value of " $a=198 \mathrm{~mm}$ " was kept, and for $a / d=3.0$, the value of " $a=594 \mathrm{~mm}$ " was kept. These control beams were tested up to an ultimate failure to work out their average elastic, elastoplastic, and plastic load values corresponding to $45 \%, 75 \%$, and $95 \%$ of ultimate load values, respectively. Details of test results are given in Table 5 . Deflection of these beams was also determined and recorded by using LVDTs (linear variable displacement transducers) with a least count $0.001 \mathrm{~mm}$. The LVDTs were placed under the soffit of beams which were further attached electronically with the computerised system. The location of these LVDTs was fixed according to the load position; that is, the 1st LVDT was placed under the loading point " $P$," the 2 nd was under the midpoint of the beam, and the 3rd was exactly at the same distance from opposite support just mirrored to the 


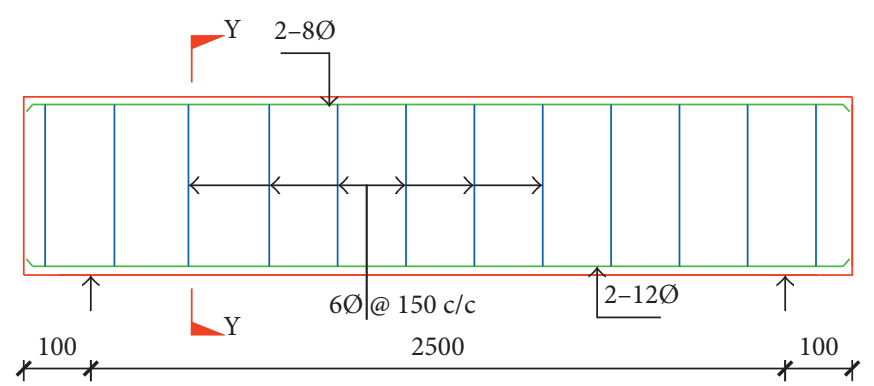

(a)

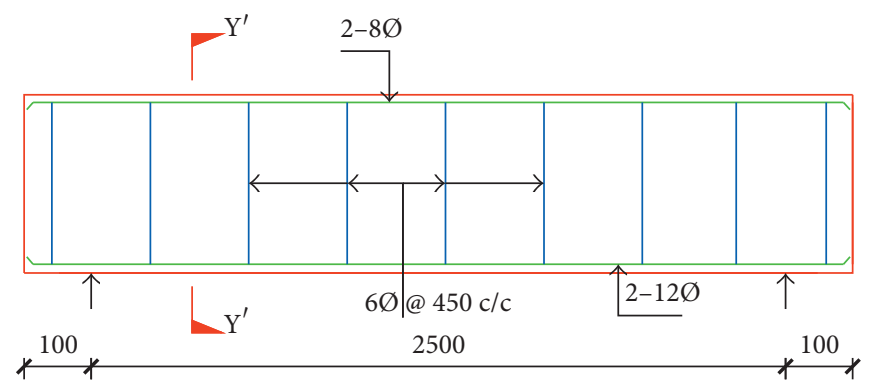

(b)
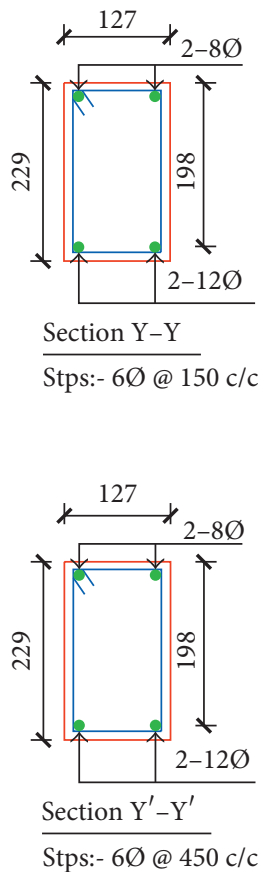

FIGURE 1: Beam section and reinforcement details: (a) shear-designed beams (DBs); (b) shear-deficient beams (SDBs).

TABLE 4: Shear-designed and shear-deficient RCC beam designation detail.

\begin{tabular}{lccc}
\hline Designation of beams & Loading description & Shear-span ratio $(a / d)$ & 1.0 \\
\hline DB-ad-1 & Shear-designed controlled beams & 1.0 & 3 \\
RDB45-ad-1 & $45 \%$ predamage + strengthening & 1.0 & 3 \\
RDB75-ad-1 & $75 \%$ predamage + strengthening & 1.0 & 3 \\
RDB95-ad-1 & $95 \%$ predamage + strengthening & 3.0 & 3 \\
DB-ad-3 & Shear-designed controlled beams & 3.0 & 3 \\
RDB45-ad-3 & $45 \%$ predamage + strengthening & 3.0 & 3 \\
RDB75-ad-3 & $75 \%$ predamage + strengthening & 3.0 & 3 \\
RDB95-ad-3 & $95 \%$ predamage + strengthening & 1.0 & 3 \\
SDB-ad-1 & Shear-deficient controlled beams & 1.0 & 3 \\
RSDB45-ad-1 & $45 \%$ predamage + strengthening & 1.0 & 3 \\
RSDB75-ad-1 & $75 \%$ predamage + strengthening & 1.0 & 3 \\
RSDB95-ad-1 & $95 \%$ predamage + strengthening & 3.0 & 3 \\
SDB-ad-3 & Shear-deficient controlled beams & 3.0 & 3 \\
RSDB45-ad-3 & $45 \%$ predamage + strengthening & 3.0 & 3 \\
RSDB75-ad-3 & $75 \%$ predamage + strengthening & 3.0 & 3 \\
RSDB95-ad-3 & $95 \%$ predamage + strengthening & & 3 \\
\hline
\end{tabular}

DB: shear-designed beam; RDB: strengthened shear-designed beam; SDB: shear-deficient beam; RSDB: strengthened shear-deficient beam.

1st LVDT (refer Figure 2). The load versus deflection curves of the 1st LVDT are only presented in this article for comparative study.

2.2.2. Predamaging of Beams. According to the test results of controlled beams, the other sets of beams were loaded on the same setup and predamaged for three different levels of initial stresses corresponding to $45 \%, 75 \%$, and $95 \%$ of the ultimate load. The DB45 and SDB45 beams were initially loaded for $45 \%$ level of damage. Similarly, DB75 and SDB75 and DB95 and SDB95 were loaded for 75\% and 95\% levels of damage, respectively. These damaged beams were then unloaded and strengthened with $20 \mathrm{~mm}$ thick U-shaped 


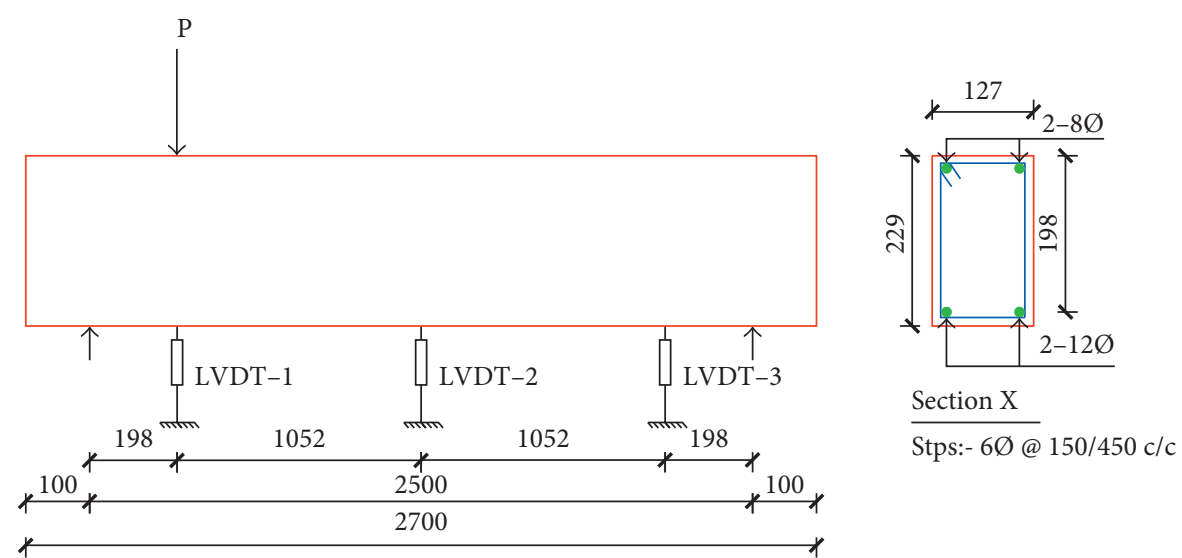

(a)
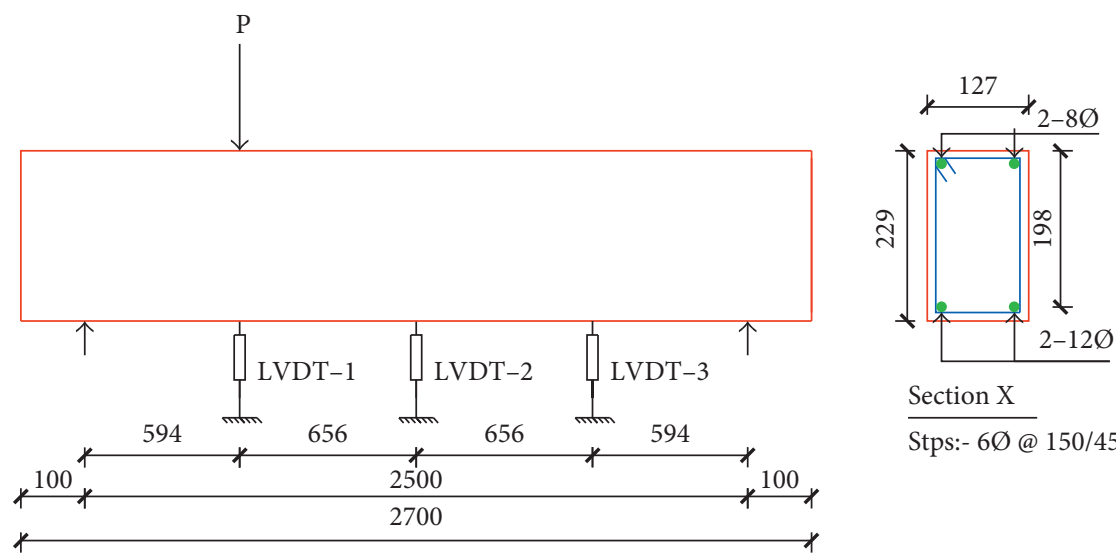

Section X

Stps:- $6 \varnothing @ 150 / 450$ c/c

(b)

FIgURE 2: Schematic diagram of the test setup: (a) beams tested at $a / d=1$; (b) beams tested at $a / d=3$.

TABLE 5: Test results of controlled DB and SDB.

\begin{tabular}{|c|c|c|c|c|c|c|}
\hline \multirow[t]{2}{*}{ Designation of beams } & \multirow[t]{2}{*}{ a/d ratio } & \multirow[t]{2}{*}{ Avg. ultimate load value $(\mathrm{kN})$} & \multirow[t]{2}{*}{ Avg. deflection at ultimate load (mm) } & \multicolumn{3}{|c|}{$\begin{array}{l}\text { Calculated load value } \\
\text { for different stress levels } \\
\qquad(\mathrm{kN})\end{array}$} \\
\hline & & & & $45 \%$ & $75 \%$ & $95 \%$ \\
\hline DB-ad-1 & 1 & 145.68 & 5.899 & 65.56 & 109.26 & 138.40 \\
\hline DB-ad-3 & 3 & 64.53 & 11.674 & 29.04 & 48.40 & 61.30 \\
\hline SDB-ad-1 & 1 & 144.28 & 6.857 & 64.93 & 108.21 & 137.07 \\
\hline SDB-ad-3 & 3 & 59.55 & 10.371 & 26.80 & 44.66 & 56.57 \\
\hline
\end{tabular}

polymer-modified ferrocement jacketing which contained $15 \%$ SBR latex and three layers of square woven steel wire mesh. The detail of strengthening is given in the subsequent section.

2.2.3. Strengthening Procedure. The behaviour of strengthened beams is highly dependent upon the surface preparation and application of the strengthening material. The repaired surface of the beams should be free from dirt, oil, dust, existing matter, and curing compounds. An improper preparation of the surface can result in debonding of PMF jacketing. Before the strengthening procedure, the beams were turned upside down to expose their soffit. The particular portion of all the predamaged beams was cleaned with a wire brush at their soffit and side faces where the jacketing is supposed to be applied. The surface was cleaned with such a way to expose the aggregates and to make the surface sufficiently rough for application of repairing mortar. Water was sprayed on the prepared surface to make it wet.

The another study done by the authors resulted that the three-layered square woven steel wire mesh PMF having an optimum percentage of $15 \%$ SBR showed better strength 

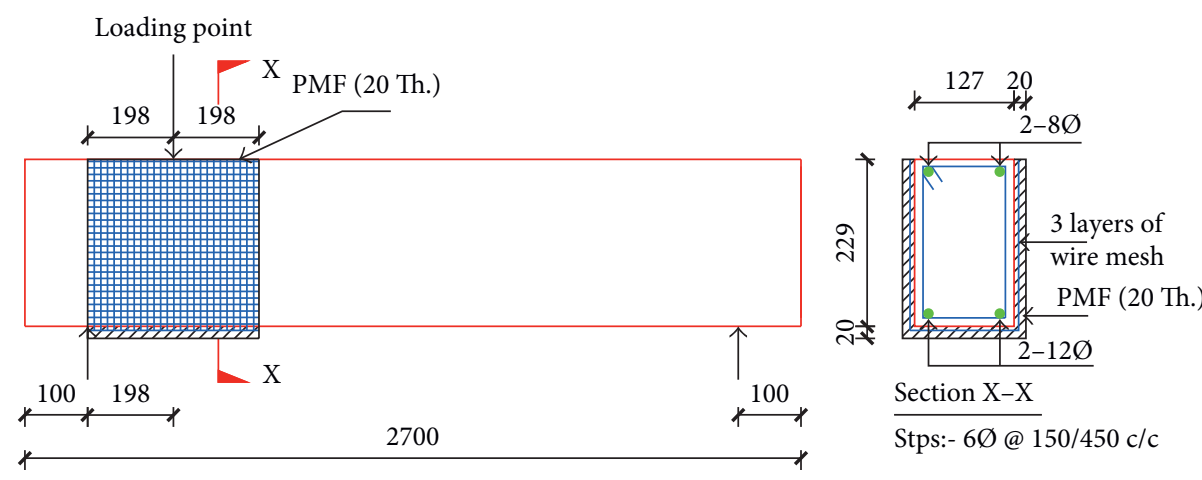

(a)
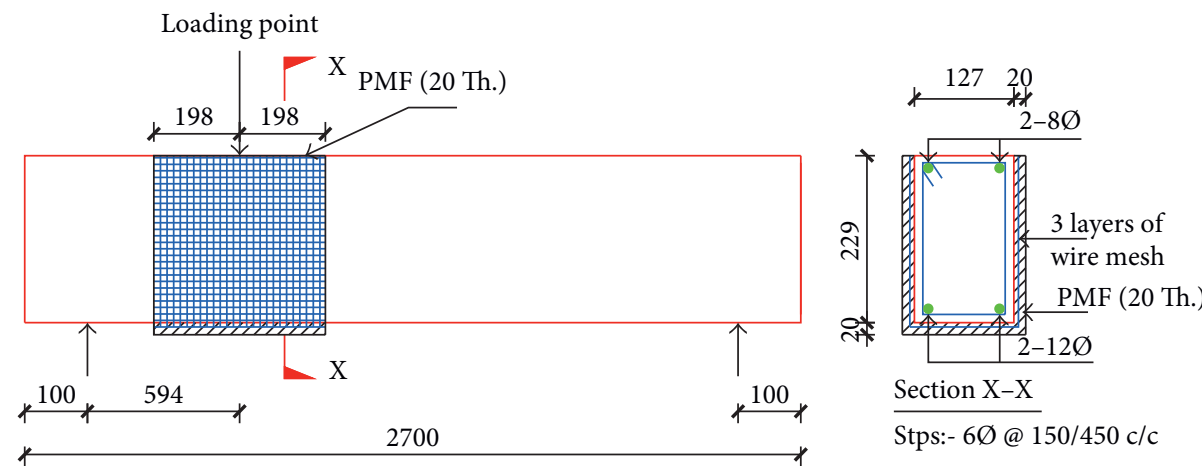

(b)

Figure 3: Detail of PMF strengthening: (a) beams tested at $a / d=1$; (b) beams tested at $a / d=3$.

properties and hence adopted in this present investigation to strengthen the predamaged RCC beams. The polymermodified repairing mortar was constituted with cement, sand, SBR, and water in the ratio of $1: 2: 0.15: 0.35$ [45]. A silicon-based antifoaming agent was also added to the polymer-modified mortar matrix. Cement slurry was used as a bonding agent. First of all, three layers of wire mesh were affixed over the specified length of beams, and then, SBRmodified mortar was applied. A total of $20 \mathrm{~mm}$ thick PMF jacketing was applied under the soffit and side faces of the beams in a length of " $2 d=396 \mathrm{~mm}$ ", centred on the loading point, for both DB- and SDB-type beams, irrespective of $a / d$ ratios. Different sets of beam specimens were prepared for each level of initial damage. The repair material was accurately positioned with the help of wooden forms. After 24 hours of application of PMF jacketing, the strengthened portion of the beams was cured with gunny bags for further 28 days. The details of PMF-strengthened beams are shown in Figure 3 and Plate 1.

2.2.4. Reloading of Predamaged Strengthened Beams. The PMF-strengthened beams were again placed on the same loading frame setups (as specified in Figure 2) to find their ultimate shear load-carrying capacities, deflection, and cracking pattern. The locations of LVDTs were kept the same as in the case of controlled beams. The load-deflection behaviour of all sets of tested beams was recorded for conclusive study and shown in Figures $4-7$. The detail of

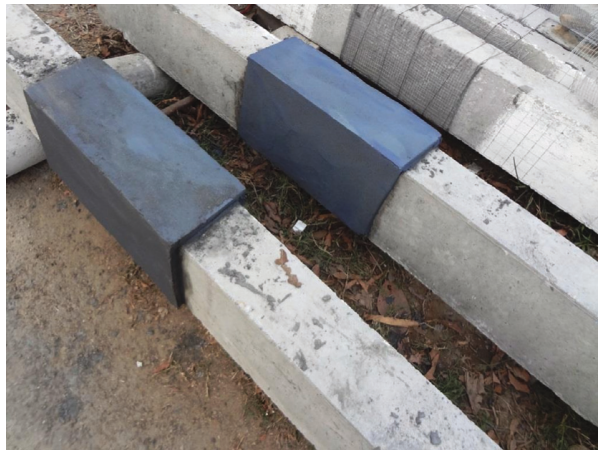

Plate 1: Application of PMF jacketing on the soffit and side faces of the beams (by turning the beams upside down).

observed loads, deflections, and failure modes is given in Table 6.

\section{Results}

In this current experimental program, a total of 48 beams were tested. The testing was aimed to achieve many objectives by comparing the behaviours of these beams. The controlled and strengthened beams were loaded up to ultimate failure. Most of the beams showed diagonal cracking patterns and the shear mode of failure. The effects of different levels of initial stresses, $a / d$ ratios, and spacing of shear stirrups on the strength, failure modes, cracking pattern, 


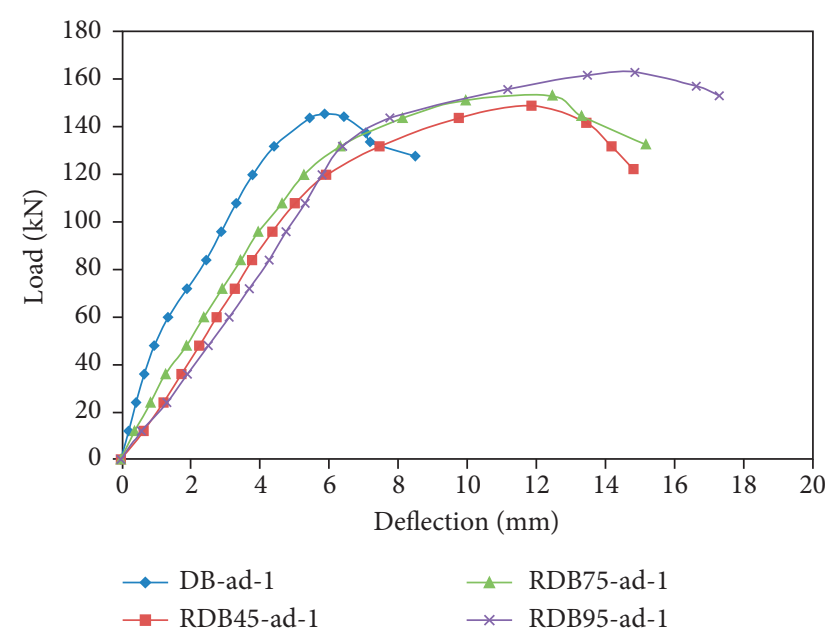

Figure 4: Load-deflection plot of shear-designed beams tested at a/d ratio 1 .

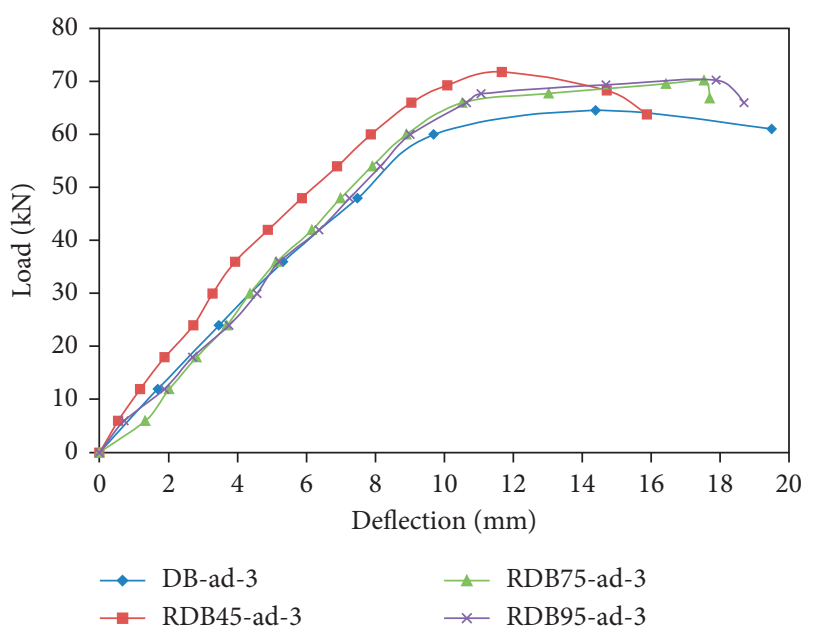

FIGURE 5: Load-deflection plot of shear-designed beams tested at a/d ratio 3 .

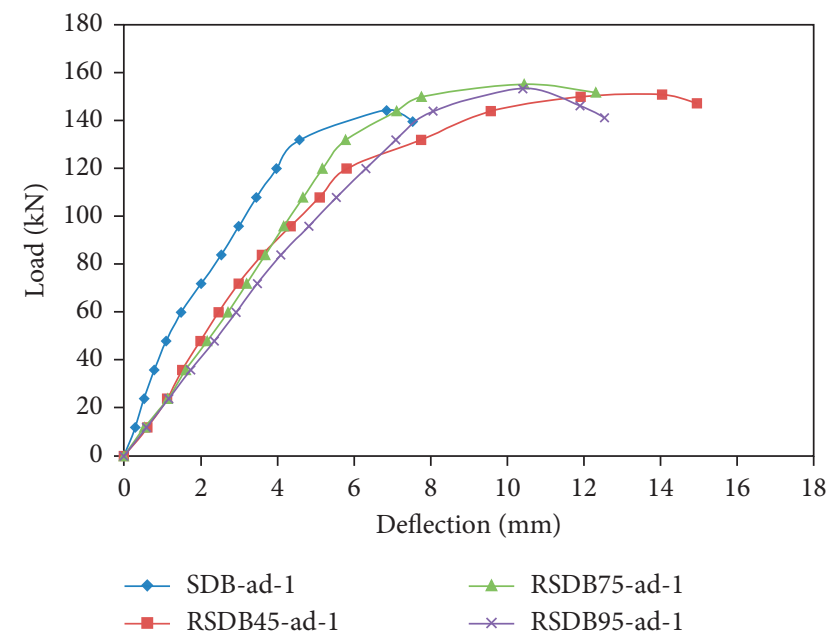

Figure 6: Load-deflection plot of shear-deficient beams tested at a/d ratio 1 .

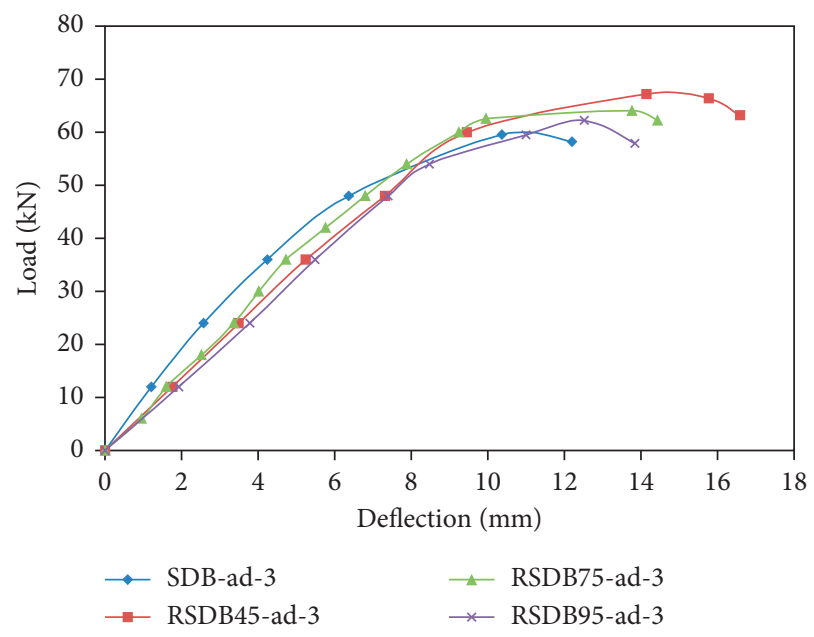

FIgURE 7: Load-deflection plot of shear-deficient beams tested at a/d ratio 3 .

ductility, and deflection of strengthened beams are discussed in the subsequent sections.

\subsection{Comparisons between Controlled and Strengthened Beams}

3.1.1. Effect of Different Levels of Initial Stresses. All the strengthened beams which were initially damaged with $45 \%$, $75 \%$, and $95 \%$ of the ultimate load had showed a complete restoration and further enhancement of the original strength up to $12.03 \%$ after strengthening. The deflection behaviour of these beams was also changed after strengthening, and the beams exhibited more ductility as compared to controlled beams. Hence, higher deflection values were observed for all the strengthened beams at the ultimate failure level.

The strengthened shear-designed beams when tested at $a / d=1.0$ and having the initial stress level of 95\% (RDB95ad-1) showed the maximum improvement in their ultimate load value by $12.03 \%$. The results of strengthened beams with an initial damage of 45\% (RDB45-ad-1) and 75\% (RDB-75ad-1) also showed a similar trend of improvement in their ultimate load values by $2.38 \%$ and $5.33 \%$, respectively, over the controlled beam DB-ad-1. The observed figures of load values were quite less for the beams tested at $a / d=3.0$, but these beams showed a similarly improved trend after strengthening. The strengthened RDB45-ad-3, RDB75-ad-3, and RDB-95-ad3 beams tested at $a / d=3.0$ demonstrated the improvement in the ultimate load by $11.19 \%, 8.82 \%$, and $8.85 \%$, respectively, with respect to the controlled beam DB-ad-3. Load-deflection comparative curves of controlled and strengthened sheardesigned beams with different levels of initial damages, when tested at $a / d=1$ and 3, are shown in Figures 4 and 5 .

The strengthened shear-deficient beams having initial damages of $45 \%, 75 \%$, and $95 \%$ were also tested for different a/d ratios. The strengthened RSDB75-ad-1 beams showed maximum improvement in their ultimate load by $7.57 \%$, when compared with the controlled beam SDB-ad-1. The RSDB45-ad-1 and RSDB95-ad-1 beams also showed an improvement in their ultimate load values by $4.60 \%$ and 
TABLE 6: Reloading test results of predamaged strengthened beams.

\begin{tabular}{lcccc}
\hline Beam description & Ultimate load $(\mathrm{kN})$ & Percentage increase in ultimate load & $\begin{array}{c}\text { Deflection } \\
\text { at ultimate load (mm) }\end{array}$ & Failure mode \\
\hline DB-ad-1 & 145.68 & - & 5.899 & 11.891 \\
RDB45-ad-1 & 149.14 & $2.38 \%$ & 12.494 & Shear \\
RDB75-ad-1 & 153.45 & $5.33 \%$ & 14.882 & Shear flexural \\
RDB95-ad-1 & 163.20 & $12.03 \%$ & 11.674 & Shear flexural \\
DB-ad-3 & 64.53 & - & 14.564 & Shear flexural \\
RDB45-ad-3 & 71.75 & $11.19 \%$ & 17.534 & Shear-flexural \\
RDB75-ad-3 & 70.22 & $8.82 \%$ & 17.887 & Shear \\
RDB95-ad-3 & 70.24 & $8.85 \%$ & 6.857 & Shear flexural \\
SDB-ad-1 & 144.28 & - & 14.048 & Shear \\
RSDB45-ad-1 & 154.60 & $4.60 \%$ & 10.450 & Shear flexural \\
RSDB75-ad-1 & 161.87 & $7.57 \%$ & 10.412 & Shear flexural \\
RSDB95-ad-1 & 155.96 & $6.29 \%$ & 10.371 & 14.146 \\
SDB-ad-3 & 59.55 & - & 13.763 & Shear flexural \\
RSDB45-ad-3 & 67.20 & $12.85 \%$ & $7.56 \%$ & 4.523 \\
RSDB75-ad-3 & 64.05 & $4.52 \%$ & & Shear \\
RSDB95-ad-3 & 62.24 & & & Shear \\
\hline
\end{tabular}

$6.29 \%$, respectively, as compared to the controlled beam SDB-ad-1. At a higher $a / d$ ratio $=3.0$, the ultimate loads also exhibited enhancement, and the maximum improvement in the load was recorded for RSDB45-ad-3 beams by $12.85 \%$ over the controlled beam SDB-ad-3. The load-carrying capacities of RSDB75-ad-3 and RSDB 95-ad-3 beams were also improved by $7.56 \%$ and $4.52 \%$, respectively. Load-deflection comparative curves of controlled and strengthened sheardeficient beams with different levels of initial stresses, when tested at $a / d=1$ and 3, are shown in Figures 6 and 7.

Test results showed that the performance of PMF jacketing is very consistent for both shear-deficient and shear-designed beams at $a / d$ ratios 1 and 3. Application of PMF jacketing filled the cracks which were developed during the initial damaging of beams and also helped to arrest the formation of such deformities during retesting of damaged strengthened beams. The PMF jacketing helped to enhance the ductility and caused to delay the shear failure of beams by resisting and distributing the applied loads. The proportional deflection of strengthened beams was also increased irrespective of their level of initial damages.

3.1.2. Effect of a/d Ratios. The controlled as well as strengthened shear-designed (DB) and shear-deficient (SDB) beams were tested for two different a/d ratios 1 and 3 to study the effect of shear span " $a$ " on the performance of these beams. From the test results, it was found that the a/d ratio played a crucial role. The strengthened beams tested at $a / d=1.0$ showed more improvement in their ultimate strength, cracking pattern, ductility, and deflection behaviour as compared to beams which were tested at $a / d=3.0$, irrespective of stirrup spacing.

The controlled shear-designed beams tested at $a / d=1.0$ (DB-ad-1) showed a higher load-carrying capacity of
$125.76 \%$ as compared to DB-ad-3 beams tested at $a / d=3$. The observed pattern for strengthened beams was also similar, and the shear load-carrying capacity of RDB45-ad-1, RDB75-ad-1, and RDB95-ad-1 beams was increased by $107.86 \%$, $118.53 \%$, and $132.35 \%$, respectively, when compared with RDB45-ad-3, RDB75-ad-3, and RDB95-ad-3 beams. Graphical comparisons of ultimate loads at different a/d ratios are shown in Figure 8.

A similar trend was recorded for controlled sheardeficient SDB-ad-1 beams, and 142.28\% higher loadcarrying capacity was observed in comparison with SDBad-3 beams. The strengthened shear-deficient beams also behaved in a similar manner, and the ultimate load values of RSDB95-ad-1 beams (tested at $a / d=1$ ) were improved to a maximum of $146.38 \%$. The RSDB45-ad-1 and RSDB75-ad1 beams showed improvement in their ultimate strength by $124.58 \%$ and $142.31 \%$, respectively, as compared to RSDB75ad-3 and RSDB95-ad-3 beams. Graphical comparisons of ultimate loads at different $a / d$ ratios are shown in Figure 9.

At an $a / d$ ratio of 1.0, the beams tend to fail in shear only, and as the $a / d$ ratio increased, the behaviour of beams was shifted to a shear-flexure mode of failure. Shear forces were dominating in the case of beams tested at $a / d=1.0$. All the controlled and strengthened beams showed more figurative strength values and a comparatively lesser deflection at a particular load level when tested at a smaller $a / d$ ratio of 1.0 as compared to the beams tested at a higher a/d ratio of 3.0. As the distance of the load point from the support was increased, the relative deflection was also increased. This is due to the parabolic shape of the deflection curve, and hence, the observed deflection values were smaller for the beams tested near the support as compared to the deflection values of the beams tested at " $3 d$ " away from the support. The observed behaviour of strengthened beams was more ductile when tested at a higher $a / d$ ratio of 3 . This improved 


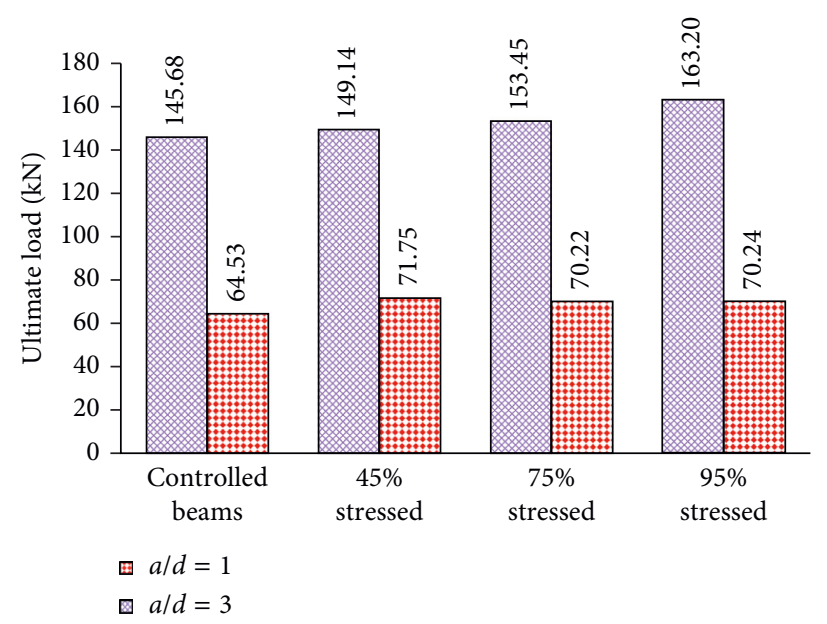

Figure 8: Comparison of ultimate loads of shear-designed beams tested at $a / d$ ratios 1 and 3.

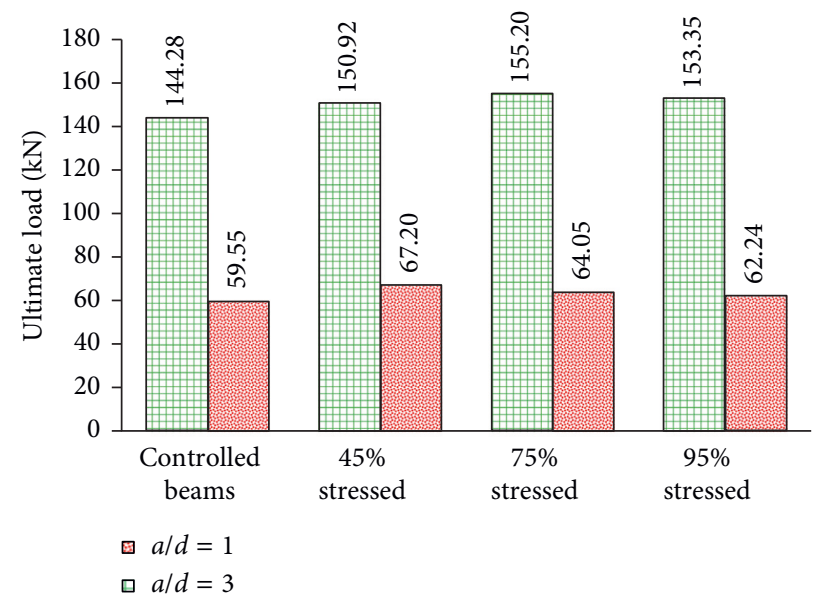

Figure 9: Comparison of ultimate loads of shear-deficient beams tested at a/d ratios 1 and 3.

ductility further imparts to increase the deflection of these beams.

It is concluded that the PMF jacketing technique contributes more towards improving the shear resistance of beams and further enhances the ultimate load values when the beams were tested at $a / d=1$. Hence, PMF jacketing delays the direct shear failure, and it apparently increases the contribution of stirrups to resist higher loads.

3.1.3. Effect of Beam Type. The beams having stirrups at a spacing of $150 \mathrm{~mm} \mathrm{c/c}$ were designated as shear-designed beams (DBs), and the beams have stirrups at a spacing of $450 \mathrm{~mm} \mathrm{c} / \mathrm{c}$ were designated as shear-deficient beams (SDBs). Both the controlled and strengthened beams were tested for two different a/d ratios. The controlled shear-deficient beams (SDB-ad-1) when tested at $a / d$ ratio $=1.0$ showed almost similar strength values as compared to controlled shear-designed beams (DB-ad-1) with a negligible decrement of $0.96 \%$ only. A similar trend was observed at $a / d=3.0$, and the SDB-ad-3 beams showed $7.72 \%$ lesser ultimate load as compared to DB-ad-3 beams. With the increase of the initial damage level, the percentage decrease in loads showed an upward trend when the beams were tested at $a / d$ ratio 3 . The observed behaviour was, however, different in the case of beams tested at $a / d=1$, and the load values firstly improved for the beams with $45 \%$ and $75 \%$ initial damages and then decreased for beams having $95 \%$ of the initial damage. The RSDB95-ad-1 beams showed $6.04 \%$ lesser load-carrying capacities as compared to RDB95-ad-1 beams. At $a / d=1.0$ and for a particular initial damage level, the strengthened shear-designed and sheardeficient beams showed almost equal strength with a minor variation of $1 \%$ to $6 \%$ only.

This is attributable to the arch action of the concrete element and the efficiency of PMF jacketing. The strengthening technique is observed to be more efficient in case of shear-deficient beams when tested at $a / d$ ratio 1 . In the event of beams tested at $a / d=3.0$, a different type of behaviour was observed, and the strengthened sheardeficient beams showed a lesser load-carrying capacity as compared to shear-designed beams for a particular damage 


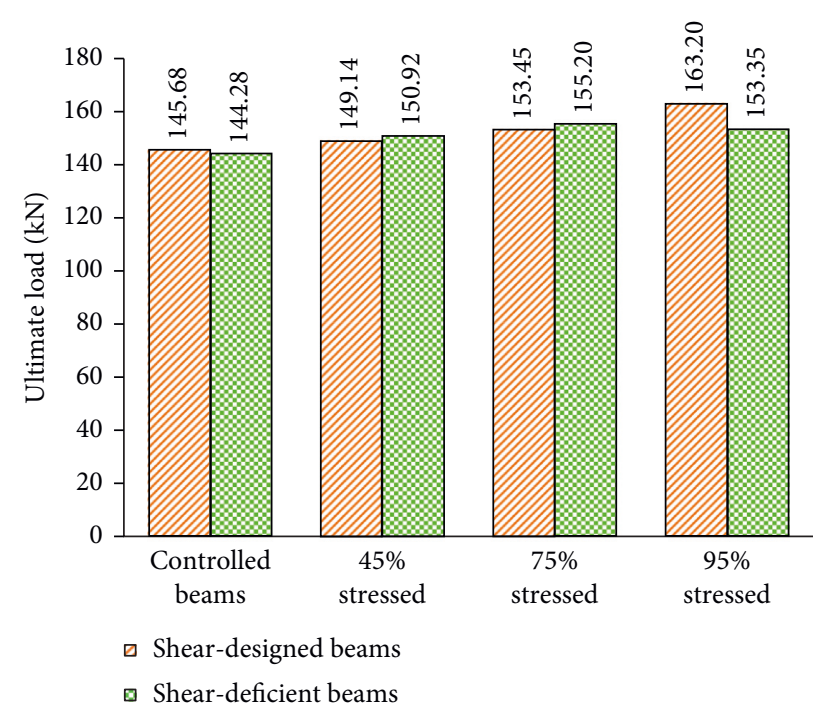

Figure 10: Comparison of ultimate loads of shear-designed and shear-deficient beams tested at a/d 1 .

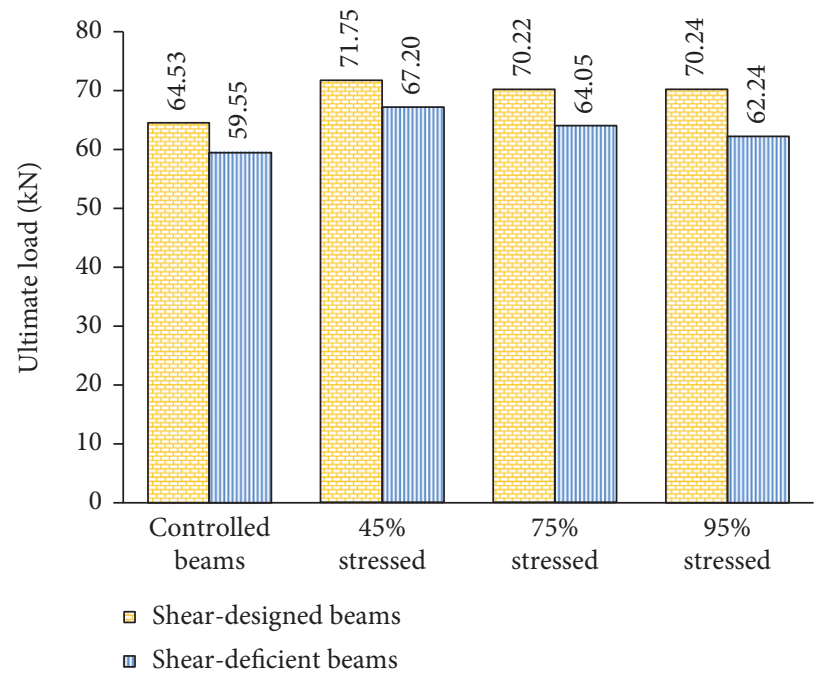

FIgURE 11: Comparison of ultimate loads of shear-designed and shear-deficient beams tested at a/d 3 .

level. Deflection behaviour was also inconsistent in both the cases. Graphical comparison of ultimate loads of beams tested at a/d ratio 1 is shown in Figure 10.

The shear-deficient strengthened beams (RSDB45-ad-1 and RSDB75-ad-1) with initial stresses of $45 \%$ and $75 \%$ showed a higher strength of $1.19 \%$ and $1.14 \%$ over the sheardesigned strengthened beams (RDB45-ad-1 and RDB75-ad-1), respectively, when tested at $a / d=1$. However, at the higher initial damage level of 95\%, strengthened RSDB95ad-1 beams reflected $6.04 \%$ lesser strength as compared to the controlled RDB95-ad-1 beams. It is clear from this observation that the PMF jacketing technique is more effective in the case of shear-deficient beams. Apparently, PMF enhanced the shear strength of concrete near the support by means of transferring the increased load to the stirrups and converting the brittle concrete failure into ductile. At $a / d=3$, the strengthened shear-deficient beams (RSDB45-ad-3, RSDB75-ad-3, and RSDB95-ad-3) showed lesser strength values by $6.34 \%, 8.79 \%$, and $11.39 \%$ as compared to strengthened shear-designed beams (RDB45-ad-3, RDB75ad-3, and RDB95-ad-3). Graphical comparison of ultimate loads of beams tested at a/d ratio 3 is shown in Figure 11.

The PMF jacketing is fully effective to restore and enhance the original strength of both types of initially damaged beams. Furthermore, in the case of shear-deficient beams, it is observed that the cracks had developed at an angle of $30^{\circ}$ to $45^{\circ}$. As the stirrups were at spaced as far as $450 \mathrm{~mm}$ $\mathrm{c} / \mathrm{c}$, many of these cracks were not interfered by the stirrups and therefore caused failure of beams in shear. The use of PMF tends to enhance the inertia and ductility of the beam section in such cases and is thus observed to cause a delay in beam failure. Hence, the observed experimental load and deflection values are higher due to the combined strength of concrete and ferrocement jacketing. The strengthened shear-deficient beams exhibited similar elastic behaviour as the strengthened shear-designed beams, 
and the beams were observed to fail in shear compression and diagonal tension.

\section{Discussion}

4.1. Comparison of Failure Load of Specimens. Failure load detail for all the tested beam specimens is given in Table 6 . Almost shear mode of failures was observed in all the beam specimens. No debonding of jacketing appeared when the PMF-strengthened beams were tested up to an ultimate failure level. These strengthened beams showed a significant improvement in their load-carrying capacities, ductility behaviours, and cracking patterns.

The ultimate load-carrying capacity of all the strengthened beams considerably improved as compared to controlled beams at both a/d ratios 1.0 and 3.0. The percentage increase in ultimate load values of shear-designed beams RDB-45ad-1, RDB-75-ad-1, and RDB-95-ad-1 tested at $a / d=1.0$ was $2.38 \%, 5.33 \%$, and $12.03 \%$, respectively. As the initial stress level of strengthened beams increased, the percentage improvement in the strength was also increased. Load enhancement behaviour was also observed for the strengthened beams tested at $a / d=3.0$, and the ultimate load values of RDB-45-ad-3, RDB-75-ad-3, and RDB95-ad-3 beams were increased by $11.19 \%, 8.82 \%$, and $8.85 \%$, respectively. At higher $a / d=3.0$, the percentage increase of load was observed to be more consistent, and all the shear-designed beams with different levels of predamages showed almost an equal improvement of shear load-carrying capacities. Graphical comparison of ultimate load values of shear-designed beams tested at $a / d$ ratios 1 and 3 is shown in Figure 12 .

The failure loads of strengthened shear-deficient beams were also considerably improved. This improvement was found to be lesser for the beams with a higher initial damage level of $95 \%$. The initially stressed shear-deficient beams almost got damaged at $95 \%$ stress level, but the strengthening technique showed its worth to restore and enhance the total load-carrying capacity of such beams. The percentage improvement in the failure load of beams RSDB45-ad-1, RSDB75-ad-1, and RSDB95-ad-1 tested at $a / d=1.0$ was $4.60 \%, 7.57 \%$, and $6.29 \%$, respectively, as compared to the controlled beam SDB-ad-1. The strengthened beams RSDB45-ad-3, RSDB75-ad-3, and RSDB95-ad-3 also showed the improvement in ultimate load values by $12.85 \%, 7.56 \%$, and $4.52 \%$, respectively, as compared to the controlled beam SDB-ad-3 when tested at $a / d$ ratio 3.0. The strengthened shear-deficient beams tested at a/d 3.0 showed more percentage improvement in ultimate loads if compared with beams tested at $a / d=1.0$. It is concluded that the PMF jacketing restores and improves the original strength of predamaged beams. Graphical comparison of ultimate load values of shear-deficient beams tested at $a / d$ ratios 1 and 3 is shown in Figure 13.

However, it was observed that some cracks appeared even through jacketing, which indicates a good bond of PMF jacketing with the existing concrete structure. However, in some cases, no cracks developed in the strengthened length where the jacketing was applied, and the failure cracks developed only in the vicinity of the jacketing edges. It

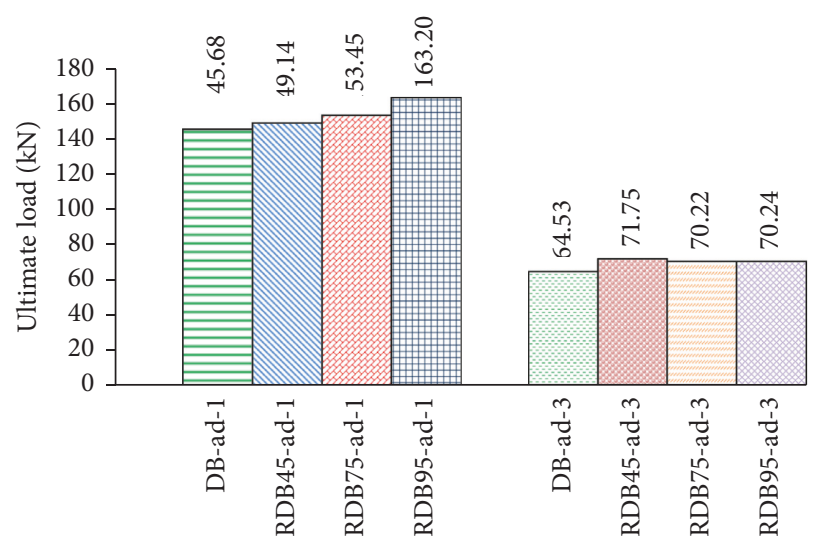

FIgURE 12: Ultimate loads of shear-designed beams tested at a/d ratios 1 and 3 .

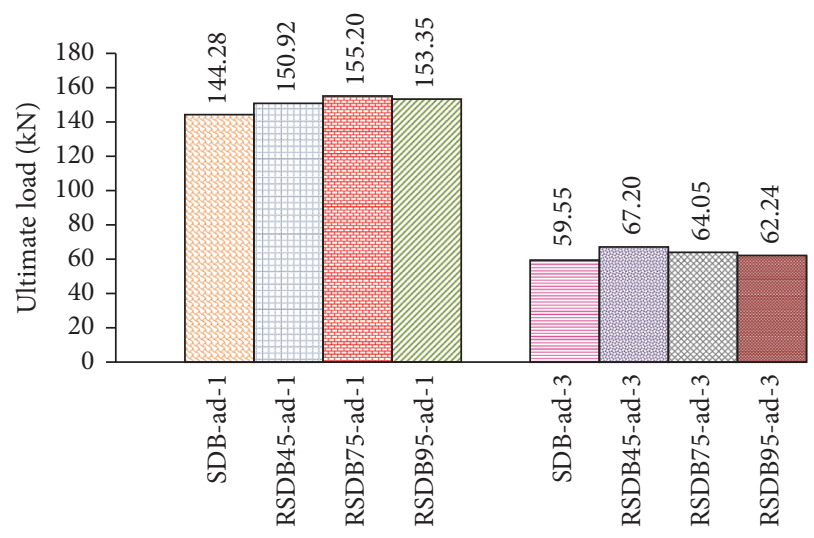

FIgURE 13: Ultimate loads of shear-deficient beams tested at a/d ratios 1 and 3 .

reflected that the PMF jacketing behaved monolithically with the concrete specimens and helped to improve the ductility of beams after strengthening.

4.2. Ductility and Deflection Behaviour of Specimens. For comparative study, the deflection values under the load point are only discussed in this article. The loaddeflection plots for all the beam specimens are shown in Figures 4-7. The ductility of both types of beams was improved after strengthening irrespective of whether the beams were tested at a/d 1.0 or 3.0. The main reason for the increase of ductility is the strengthening technique only. Strengthening of beams improved the section modulus of beams and made the beams more ductile to resist deflection even after initial damages, and hence, the beams showed higher deflection values as compared to controlled beams at any particular load level. It is concluded that the PMF increases the ductility of predamaged strengthened beams which further imparts to sustain higher deflection and applied loads.

4.3. Cracking Pattern and Failure Mechanism. A few number of cracks of varying width and spacing were observed in 


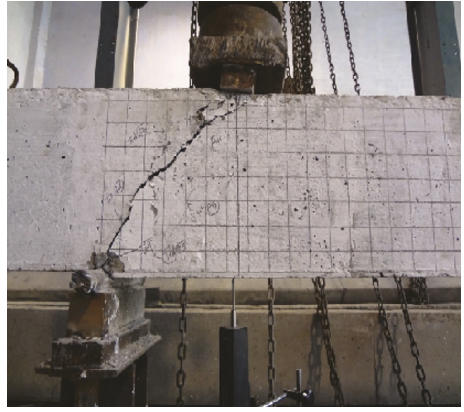

(a)

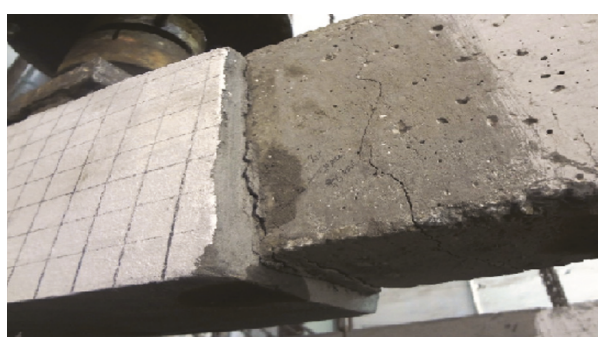

(c)

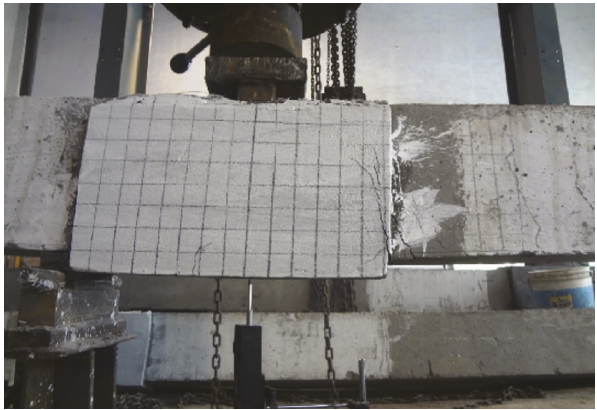

(b)

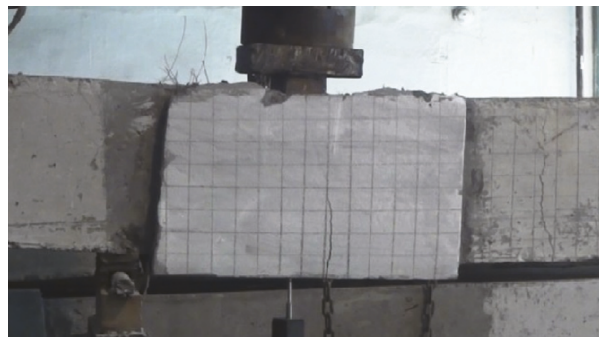

(d)

Plate 2: Shear-designed beams tested at $a / d=1$ : (a) DB-ad-1; (b) RDB45-ad-1; (c) RDB75-ad-1; (d) RDB95-ad-1.

both types of control beams. The beams ultimately failed because of the widening of any of these cracks. On the other hand, the predamaged strengthened beams showed fewer hairline cracks during testing. The strengthened beams ultimately failed due to the formation of inclined shear cracks. These beams showed minor cracks when compared with the control beams of that particular segment. Plates $2-5$ show the cracking pattern of sheardesigned and shear-deficient controlled and strengthened beams tested at $a / d=1$ and 3 .

The tested beams got cracked, apparently due to two different conditions. In some cases, the cracks appeared diagonally near the support mostly because of shear forces, and in others, the cracks appeared towards centre due to shear forces together with some flexure moment. Most of the beams tested at $a / d$ ratio 1.0 showed cracks of the first type which are described as shear compressive and diagonal tension cracks. In this mode of failure, the inclined cracks propagate rapidly due to inadequate shear reinforcement and cause the failure of concrete from the edge of the crack (refer Plates 2(a) and 4(a)). With the increase of the a/d ratio to 3.0 , the observed crack pattern was of the other type which results due to a combination of shear force and flexure moment (refer Plates 3(a) and 5(a)).

In the case of both shear-designed and shear-deficient beams when tested at $a / d=1.0$, the first crack appeared almost in the region where the shear force was maximum and the bending moment was negligible, that is, in a shear span " $a$ " which is equal to " $d=198 \mathrm{~mm}$ " for $a / d$ ratio 1.0 . The cracks aligned with one another and inclined to the axis of the beam at an angle between $30^{\circ}$ and $45^{\circ}$. It was observed that these cracks belonged to the first type, that is, mostly due to shear forces. As the load increased, further cracks appeared in the zone of lesser shear stresses, that is, towards the centre of beams, and nonlinearity of the load-deflection behaviour increased. With the further increase of the load, more and more cracks developed and a dominant crack propagated towards the point of loading, resulting in ultimate failure. From the loaddeflection plots, it is observed that the behaviour of beams remained linear up to a certain point, and after that, it changed into nonlinear.

The shear mode of failure was observed in the tested beams, and most of the cracks developed near the support and loading point (refer Plates 2-5). The cracking pattern of shear-designed and shear-deficient beams was changed as the a/d ratio changed from 1.0 to 3.0. It was observed that the shear-deficient controlled beams failed in a typical shear mode when tested at $a / d=1.0$. The shear-designed controlled beam DB-ad-3 was observed to behave like DBad-1, but in this case, the cracks were not only in the shear zone, but some hairline cracks also developed towards the centre of the beam. These cracks were in the region of bending moment, and as such, these beams were in the combined mode condition. These cracks further grew and followed a bent path indicating a valid contribution of flexure moment in such cases. Further increasing of the load caused the development of a dominant crack towards the reduced compression zone. The response of sheardesigned beams was generally ductile when tested at $a / d=3.0$. Aggregate interlocking, dowel action of longitudinal bars, and bond strength of concrete also impart to resist the stresses which were further induced due to the widening of cracks. However, it is difficult to estimate the exact contribution of these different components. 


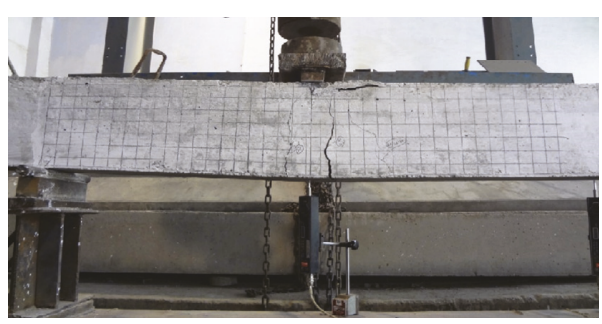

(a)

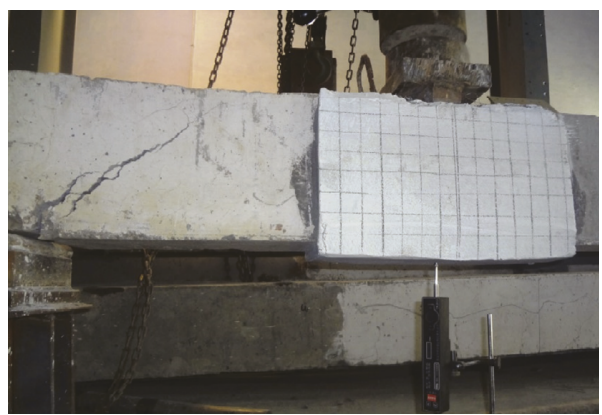

(c)

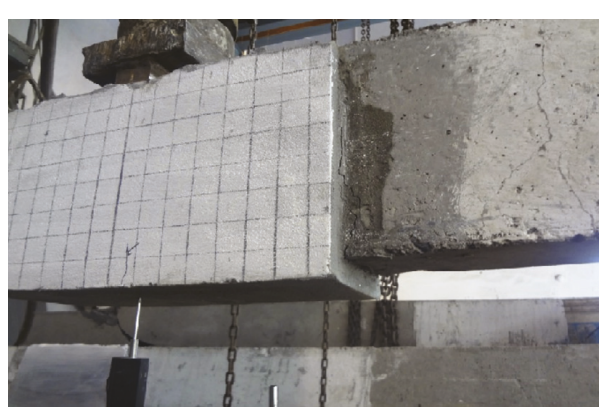

(b)

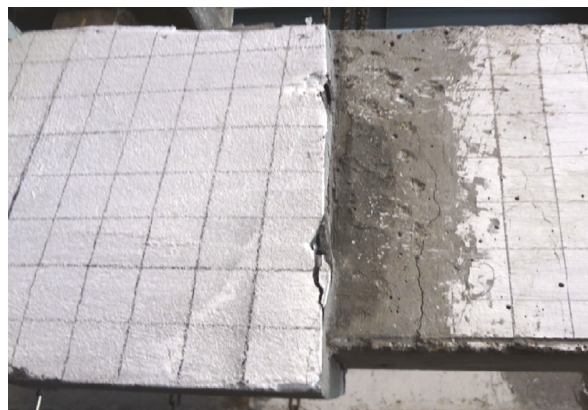

(d)

Plate 3: Shear-designed beams tested at $a / d=3$ : (a) DB-ad-3; (b) RDB45-ad-3; (c) RDB75-ad-3; (d) RDB95-ad-3.

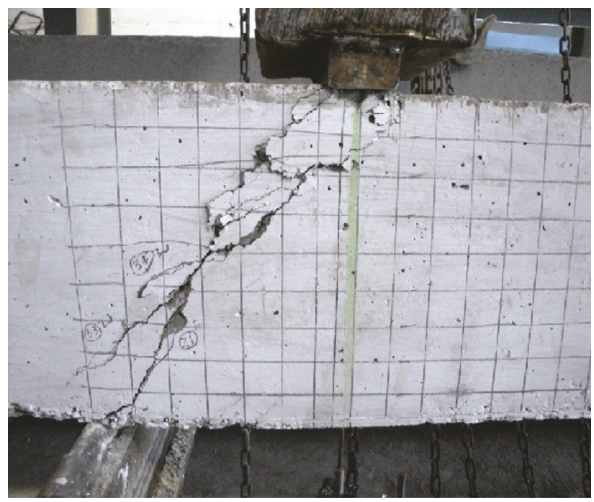

(a)

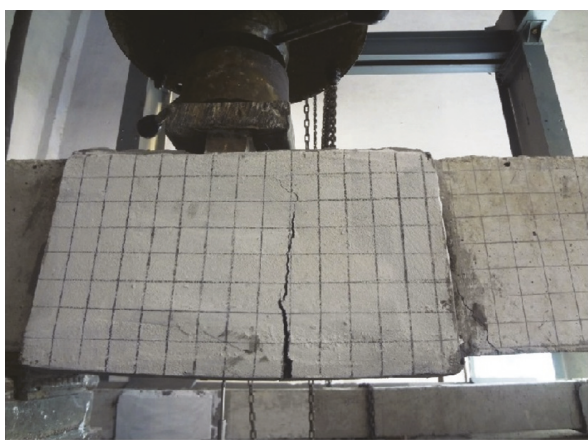

(c)

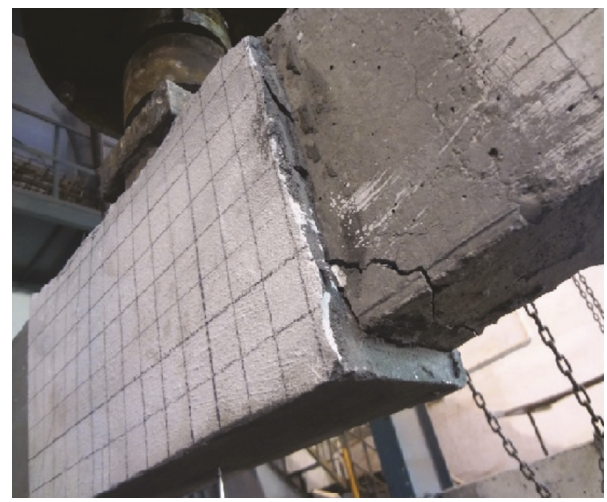

(b)

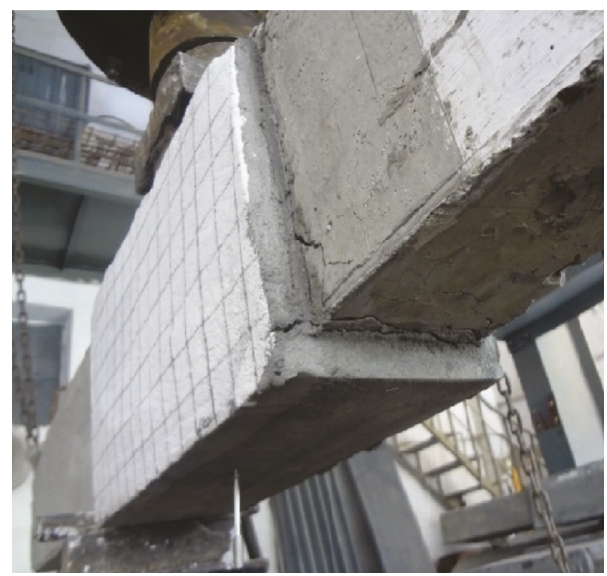

(d)

Plate 4: Shear-deficient beams tested at $a / d=1$ : (a) SDB-ad-1; (b) RSDB45-ad-1; (c) RSDB75-ad-1; (d) RSDB95-ad-1. 


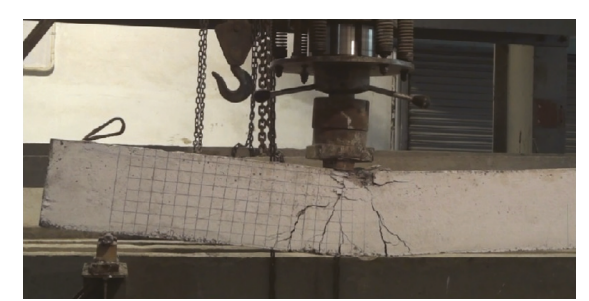

(a)

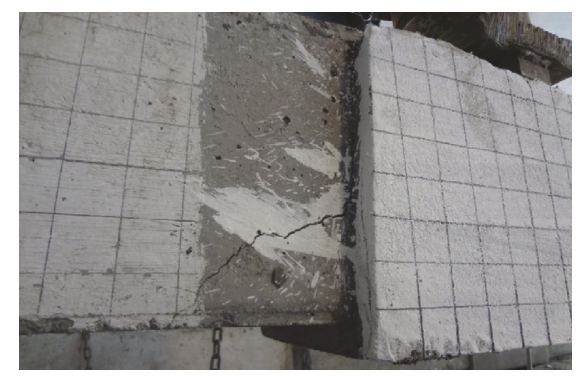

(c)

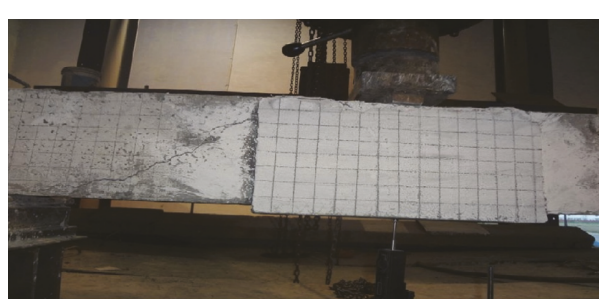

(b)

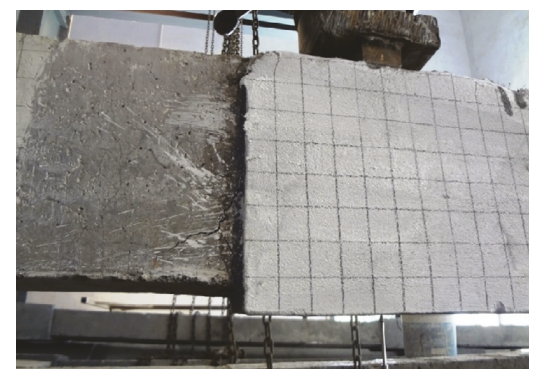

(d)

Plate 5: Shear-deficient beams tested at $a / d=3$ : (a) SDB-ad-3; (b) RSDB45-ad-3; (c) RSDB75-ad-3; (d) RSDB95-ad-3.

The behaviour of all the strengthened beams with different levels of initial damages was observed experimentally, and it was found that the jacketing neutralised the opening of cracks. The strengthened beams behaved stiffer as compared to the corresponding beams without strengthening, and the rate of crack development was also reduced. PMFstrengthened beams further displayed a lesser number of cracks when loaded to failure. This strengthening technique helps to improve the ductility of beams and causes to delay the formation of cracks. As a result, the figurative deflection of predamaged strengthened beams also enhanced. Spalling of concrete in the vicinity of the support point also reduced because of strengthening. PMF jacketing acted monolithically with the RCC beam specimens, and no bond failure was observed during the testing process. However, some cracks were found near the edge of jacketing which are attributable to the differential characteristics of strengthened beams at the newly created intersection of jacketed and unjacketed sections.

The shear failure mechanism of RCC beams is a complicated phenomenon because of interlinking of many factors such as loading pattern, shear-span ratio, beam section, the strength of concrete, and the quantity of shear and bending reinforcement. The characteristic of shear failure is abrupt as compared to the flexural failure. However, the PMF jacketing technique leads to achieve the ductile failure of strengthened beam specimens. From the abovementioned experiments, it is concluded that the PMF strengthening technique has improved the deformation behaviour, the cracking pattern, and the ultimate shear loadcarrying capacity of the initially damaged beams.

\section{Conclusions}

The following conclusions have been drawn from this experimental study:
(1) PMF is fully effective to restore and enhance the original strength of initially stressed beams even after 95\% damage. All the strengthened beams showed a complete restoration of original strength irrespective of stirrup spacing, the level of initial damage, and $a / d$ ratios. Maximum enhancement in the ultimate load value was observed as $12.03 \%$ for RDB95ad-1 beams.

(2) PMF jacketing causes to delay the direct shear failure of beams and apparently increases the contribution of stirrups to resist more loads. This technique is found to be more efficient in case of shear-deficient beams.

(3) The PMF strengthening technique increased the ductility of predamaged beams and caused to delay the shear failure by resisting and distributing the applied loads. The beams behaved more elastically, and deflection behaviour also improved after strengthening.

(4) The rate of crack development was also reduced, and the strengthened beams displayed a less number of cracks as compared to the corresponding beams without strengthening.

(5) No bond failure of jacketing was observed which reflects the proper bonding and compatibility of polymer-modified ferrocement with the concrete structures.

\section{Conflicts of Interest}

The authors declare no conflicts of interest.

\section{Acknowledgments}

The authors pay the heartiest gratitude to Sika India Pvt. Ltd. for supplying the SBR latex polymer. 


\section{References}

[1] S. F. A. Rafeeqi, S. H. Lodhi, and Z. R. Wadalawala, "Behaviour of reinforced concrete beams strengthened in shear," Journal of Ferrocement, vol. 35, no. 1, pp. 479-489, 2005.

[2] H. A. Ezz-Eldeen, "An experimental study on strengthening and retrofitting of damaged reinforced concrete beams using steel wire mesh and steel angles," International Journal of Engineering Research and Technology, vol. 4, no. 5, pp. 164173, 2015.

[3] M. B. S. Alferjani, A. A. B. A. Samad, B. S. Elrawaff, N. B. Mohamad, and M. H. B. Ahmad, "Shear strengthening of reinforced concrete beams using carbon fiber reinforced polymer laminate: a review," American Journal of Civil Engineering, vol. 2, no. 1, pp. 1-7, 2014.

[4] S. B. Singh, "Shear response and design of RC beams strengthened using CFRP laminates," International Journal of Advanced Structural Engineering, vol. 5, no. 1, pp. 1-16, 2013.

[5] S. Ahmad, A. Elahi, S. A. Barbhuiya, and Y. Farid, "Use of polymer modified mortar in controlling cracks in reinforced concrete beams," Construction and Building Materials, vol. 27, no. 1, pp. 91-96, 2012.

[6] H. R. Ronagh and A. Eslami, "Flexural retrofitting of RC buildings using GFRP/CFRP - a comparative study," Composites Part B: Engineering, vol. 46, pp. 188-196, 2012.

[7] H. S. Kim and Y. S. Shin, "Flexural behavior of reinforced concrete (RC) beams retrofitted with hybrid fiber reinforced polymers (FRPs) under sustaining loads," Composite Structures, vol. 93, no. 2, pp. 802-811, 2011.

[8] Y. T. Obaidat, S. Heyden, O. Dahlblom, G. Abu-Farsakh, and Y. Abdel-Jawad, "Retrofitting of reinforced concrete beams using composite laminates," Construction and Building Materials, vol. 25, no. 2, pp. 591-597, 2011.

[9] S. Kothandaraman and G. Vasudevan, "Flexural retrofitting of RC beams using external bars at soffit level-an experimental study," Construction and Building Materials, vol. 24, no. 11, pp. 2208-2216, 2010.

[10] P. P. Bansal, M. Kumar, and S. K. Kaushik, "Effect of type of wire mesh on strength of beams retrofitted using ferrocement laminates," National Building Materials and Construction, vol. 2, no. 1, pp. 272-278, 2008.

[11] S. A. Sheikh, D. DeRose, and J. Mardukhi, "Retrofitting of concrete structures for shear and flexure with fiber-reinforced polymers," ACI Structural Journal, vol. 99, no. 4, pp. 451-459, 2002.

[12] Y. C. Wang and K. Hsu, "Design recommendations for the strengthening of reinforced concrete beams with externally bonded composite plates," Composite Structures, vol. 88, no. 2 , pp. 323-332, 2009.

[13] M. Z. Jumaat and M. A. Alam, "Behaviour of U and L shaped end anchored steel plate strengthened reinforced concrete beams," European Journal of Scientific Research, vol. 22, no. 2, pp. 184-196, 2008.

[14] P. P. Bansal, M. Kumar, M. Kaur, and S. Kaushik, "Effect of different bonding agents on strength of retrofitted beams using ferrocement laminates," Indian Concrete Journal, vol. 80, no. 8, pp. 36-42, 2006.

[15] S. Sheela and B. Anu Geetha, "Studies on the performance of RC beam-column joints strengthened using different composite materials," Journal of the Institution of Engineers (India): Series A, vol. 93, no. 1, pp. 63-71, 2012.

[16] M. Jumaat and A. Alam, "Flexural strengthening of reinforced concrete beams using ferrocement laminate with skeletal bars," Journal of Applied Sciences Research, vol. 2, no. 9, pp. 559-566, 2006.

[17] K. Eswaran, J. Sridhar, N. Karunya, and R. A. Ranee, "Study on strengthening of predamaged reinforced concrete beam using ferrocement laminates-a review," International Research Journal of Engineering and Technology, vol. 3, no. 3, pp. 325-331, 2016.

[18] N. Karunya, R. A. Ranee, K. Eswaran, and J. Sridhar, "Study on flexural strengthening of RC beams using ferrocement laminates with Recron-3S fibre-a review," International Research Journal of Engineering and Technology, vol. 3, no. 2, pp. 199-205, 2016.

[19] S. R. Dakhane, K. P. Gatlewar, A. G. Bahale, and A. D. Raut, "Review on analysis of ferrocement-construction material," in Proceedings of the International Conference on Science and Technology for Sustainable Development (ICSTSD)-2016, pp. 88-93, Kuala Lumpur, Malaysia, May 2016.

[20] S. U. Khan, S. Rafeeqi, and T. Ayub, "Strengthening of RC beams in flexure using ferrocement," Iranian Journal of Science and Technology, Transactions of Civil Engineering, vol. 37, pp. 353-365, 2013.

[21] S. S. Patil, R. Ogale, and A. K. Dwivedi, "Performances of chicken mesh on strength of beams retrofitted using ferrocement jackets," Journal of Engineering, vol. 2, no. 7, pp. 1-10, 2012.

[22] M. V. Reddy and E. Maheshwar, "Rehabilitation of shear deficient RC beams," International Journal of Earth Sciences and Engineering, vol. 4, no. 6, pp. 1125-1128, 2011.

[23] P. R. Kumar, T. Oshima, S. Mikami, and T. Yamazaki, "Seismic retrofit of square reinforced concrete piers by ferrocement jacketing," Structure and Infrastructure Engineering, vol. 1, no. 4, pp. 253-262, 2005.

[24] O. Lalaj, Y. Yardım, and S. Yılmaz, "Recent perspectives for ferrocement," Research on Engineering Structures and Materials, vol. 1, no. 1, pp. 11-23, 2015.

[25] A. E. Naaman, Ferrocement and Laminated Cementitious Composites, Vol. 3000, Techno Press, Ann Arbor, MI, USA, 2000.

[26] N. Rengaswamy, V. Saraswathy, and K. Balakrishnan, "Studies on the effect of an inhibitor admixture in ferrocement," Journal of Ferrocement, vol. 22, no. 4, pp. 359-371, 1992.

[27] C. L. C. Roxas, R. S. Gallardo, B. Teodosio, E. K. T. Ochosa, and S. E. Young, "Durability of ferrocement garbage disposal barge," in Proceedings of the DLSU Research Congress 2013, pp. 1-7, De La Salle University, Manila, Philippines, March 2013.

[28] L. Andal, M. Palanichamy, and M. Sekar, "Strength and durability of polymer and fly ash modified ferrocement roofing/flooring elements," in Proceedings of the 33rd Conference on Our World in Concrete \& Structures, vol. 25, Singapore, August 2008.

[29] X. M. Kong, C. C. Wu, Y. R. Zhang, and J. L. Li, "Polymermodified mortar with a gradient polymer distribution: preparation, permeability, and mechanical behaviour," Construction and Building Materials, vol. 38, pp. 195-203, 2013.

[30] M. Ramli and A. A. Tabassi, "Effects of polymer modification on the permeability of cement mortars under different curing conditions: a correlational study that includes pore distributions, water absorption and compressive strength," Construction and Building Materials, vol. 28, no. 1, pp. 561-570, 2012.

[31] R. Wang, P. M. Wang, and L. J. Yao, "Effect of redispersible vinyl acetate and versatate copolymer powder on flexibility of cement mortar," Construction and Building Materials, vol. 27, no. 1, pp. 259-262, 2012. 
[32] S. Marceau, F. Lespinasse, J. Bellanger, C. Mallet, and F. Boinski, "Microstructure and mechanical properties of polymer-modified mortars," European Journal of Environmental and Civil Engineering, vol. 16, no. 5, pp. 571-581, 2012.

[33] Z. Zhang, P. Wang, and J. Wu, "Dynamic mechanical properties of eva polymer-modified cement paste at early age," Physics Procedia, vol. 25, pp. 305-310, 2012.

[34] J. Chen, S. Zhang, J. Y. Liu, and X. R. Zhou, "Preparation and properties of cement mortar modified by VAE latex," Advanced Materials Research, vol. 306-307, pp. 913-916, 2011.

[35] Y. Y. Wu, B. G. Ma, J. Wang, F. C. Zhang, and S. W. Jian, "Study on interface properties of EVA-modified cement mortar," Advanced Materials Research, vol. 250-253, pp. 875-880, 2011.

[36] N. Žižková, R. Drochytka, and K. Nosek, "Polymer-modified mortars for surface treatment with the utilization of waste polystyrene," Key Engineering Materials, vol. 466, pp. 141-150, 2011.

[37] M. Y. L. Chew, P. P. Tan, and Y. S. Yeo, "Effect of styrene acrylic ester polymer on mortar render properties," Architectural Science Review, vol. 47, no. 1, pp. 43-52, 2004.

[38] B. Vektaris, E. Smetonaite, and V. Vilkas, "The influence of polymer latex and silica fume additives on the properties of cement mortar and concrete," Journal of Civil Engineering and Management, vol. 9, no. 2, pp. 146-152, 2003.

[39] Y. Ohama, Handbook of Polymer-Modified Concrete and Mortars: Properties and Process Technology, Noyes Publications, Saddle River, NJ, USA, 1995.

[40] S. Sheela and N. Ganesan, "Cracking characteristics of polymer modified ferrocement flexural elements," International Journal of Emerging Technology and Advanced Engineering, vol. 4, no. 4, pp. 901-911, 2014.

[41] C. B. Cheah and M. Ramli, "Load capacity and crack development characteristics of HCWA-DSF high strength mortar ferrocement panels in flexure," Construction and Building Materials, vol. 36, pp. 348-357, 2012.

[42] M. Ramli and A. A. Tabassi, "Mechanical behaviour of polymer-modified ferrocement under different exposure conditions: an experimental study," Composites Part B: Engineering, vol. 43, no. 2, pp. 447-456, 2012.

[43] V. Bhikshma, R. Kishore, and R. Srinivas, "Durability of polymer and fly ash modified ferro cement elements," Procedia Engineering, vol. 14, pp. 2642-2649, 2011.

[44] S. Sheela and M. S. Ajith, "Flexural behaviour of polymer modified ferrocement elements in chloride environment," in Proceedings of the 3rd International Conference on the Durability of Concrete Structures, pp. 1-6, Queen's University, Belfast, Northern Ireland, September 2012.

[45] R. Ghai, P. P. Bansal, and M. Kumar, "Mechanical properties of styrene-butadiene-rubber latex (SBR) and vinyl-acetateethylene (VAE) polymer modified ferrocement (PMF)," Journal of Polymer Materials, vol. 33, no. 1, pp. 111-126, 2016.

[46] A. S. Ali, H. S. Jawad, and I. S. Majeed, "Improvement the properties of cement mortar by using styrene butadiene rubber polymer," Journal of Engineering and Development, vol. 16, no. 3, pp. 61-72, 2012.

[47] R. Wang and P. M. Wang, "Application of styrene-butadiene rubber in cement-based materials," Advanced Materials Research, vol. 306-307, pp. 588-593, 2011.

[48] Z. J. Wang, R. Wang, and Y. B. Cheng, "Mechanical properties and microstructures of cement mortar modified with styrenebutadiene polymer emulsion," Advanced Materials Research, vol. 168-170, pp. 190-194, 2011.
[49] G. Barluenga and F. Hernández-Olivares, "SBR latex modified mortar rheology and mechanical behaviour," Cement and Concrete Research, vol. 34, no. 3, pp. 527-535, 2004.

[50] D. R. Kumar and B. Vidivelli, "Acrylic rubber latex in ferrocement for strengthening reinforced concrete beams," American Journal of Engineering and Applied Sciences, vol. 3, no. 2, pp. 277-285, 2010.

[51] D. R. Kumar and B. Vidivelli, "Performances of SBR latex modified ferrocement for repairing reinforced concrete beams," Australian Journal of Basic and Applied Sciences, vol. 4, no. 3, pp. 520-531, 2010.

[52] H. P. Liao and S. S. Fang, "An experimental study on flexural behavior of reinforced concrete beams strengthened with high-performance ferrocement," Advanced Materials Research, vol. 163-167, pp. 3772-3776, 2010.

[53] B. Hughes and N. Evbuomwan, "Polymer-modified ferrocement enhances strength of reinforced concrete beams," Construction and Building Materials, vol. 7, no. 1, pp. 9-12, 1993.

[54] C. Y. Zhao, S. M. Huang, Q. L. Yao, and Y. J. Chen, "Research on shearing performance of RC beams strengthened with steel wire-polymer mortar," Applied Mechanics and Materials, vol. 166-169, pp. 1702-1708, 2012.

[55] IS: 1489 (Part 1)-1991, Portland-Pozzolana Cement Specification, Bureau of Indian Standards, New Delhi, India, 1991.

[56] IS: 383-1970, Specification for Coarse and Fine Aggregates from Natural Sources for Concrete, Bureau of Indian Standards, New Delhi, India, 2002.

[57] IS 2386 (Part III)-1963, Methods of Test for Aggregates for Concrete, Bureau of Indian Standards, New Delhi, India, 1997.

[58] ACI Committee 549 (ACI 549.1R-93), "Guide for the Design, Construction, and Repair of Ferrocement," American Concrete Institute, Detroit, MI, USA, 1999.

[59] Sika ${ }^{\circledR}$ Latex Power, "SBR Based Multipurpose Polymer for Waterproofing and Repair," Sika India Pvt. Ltd, Kolkata, India.

[60] M. Afridi, Y. Ohama, M. Z. Iqbal, and K. Demura, "Water retention and adhesion of powdered and aqueous polymermodified mortars," Cement and Concrete Composites, vol. 17, no. 2, pp. 113-118, 1995.

[61] IS 10262-2009, Concrete Mix Proportioning-Guidelines, Bureau of Indian Standards, New Delhi, India, 2009.

[62] ASTM C 1437-07, Standard Test Method for Flow of Hydraulic Cement Mortar, ASTM International, West Conshohocken, PA, USA, 2007.

[63] IS 456:2000, Plain and Reinforced Concrete-Code of Practice, Bureau of Indian Standards, New Delhi, India, 2000. 


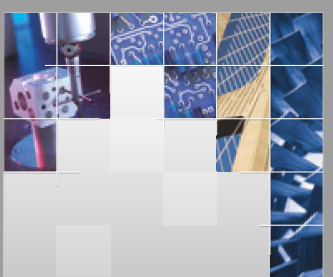

\section{Enfincering}
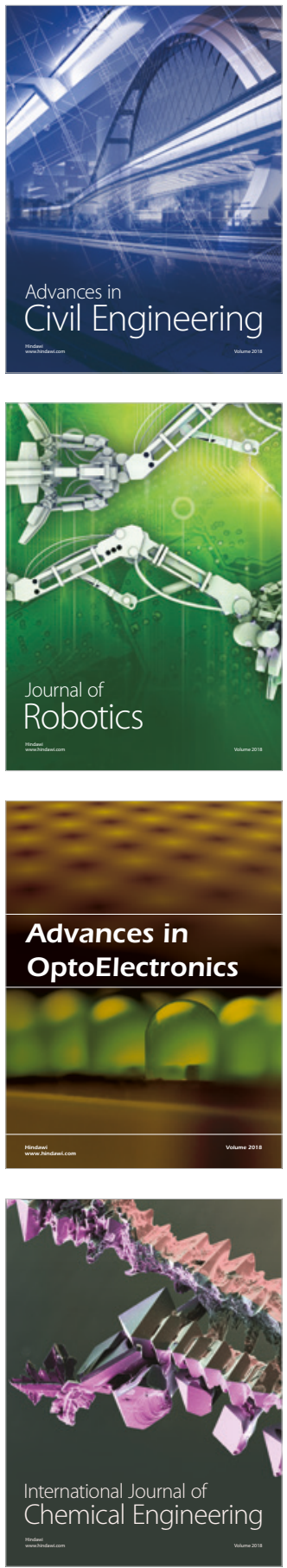

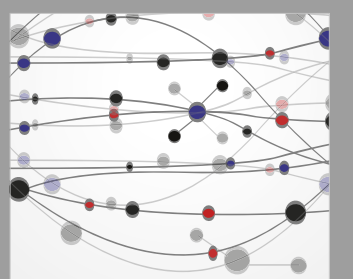

\section{Rotating \\ Machinery}

The Scientific World Journal

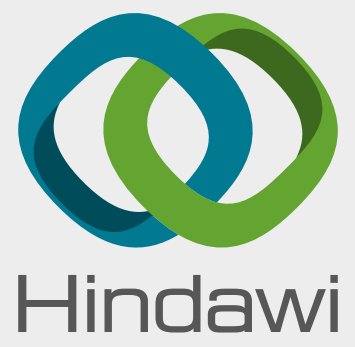

Submit your manuscripts at

www.hindawi.com
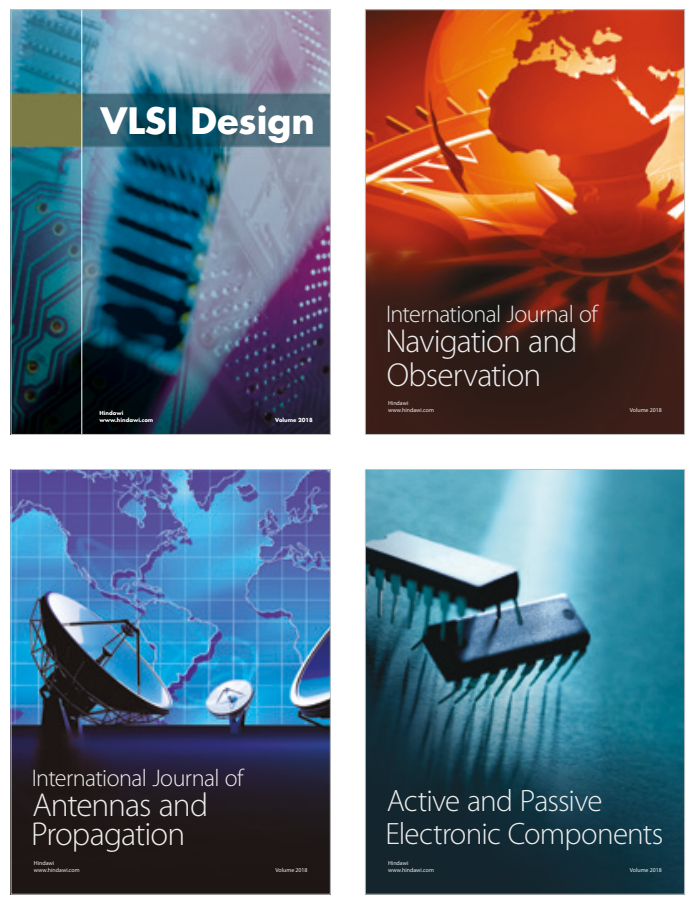
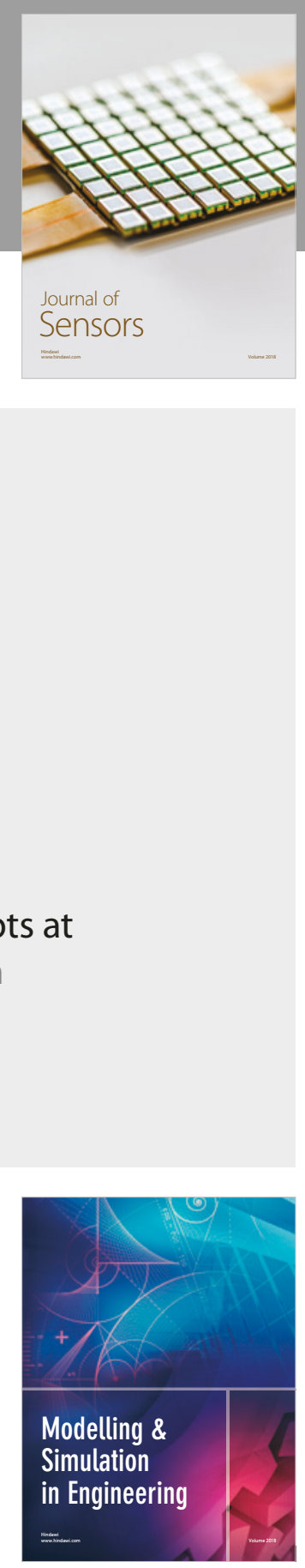

\section{Advances \\ Multimedia}
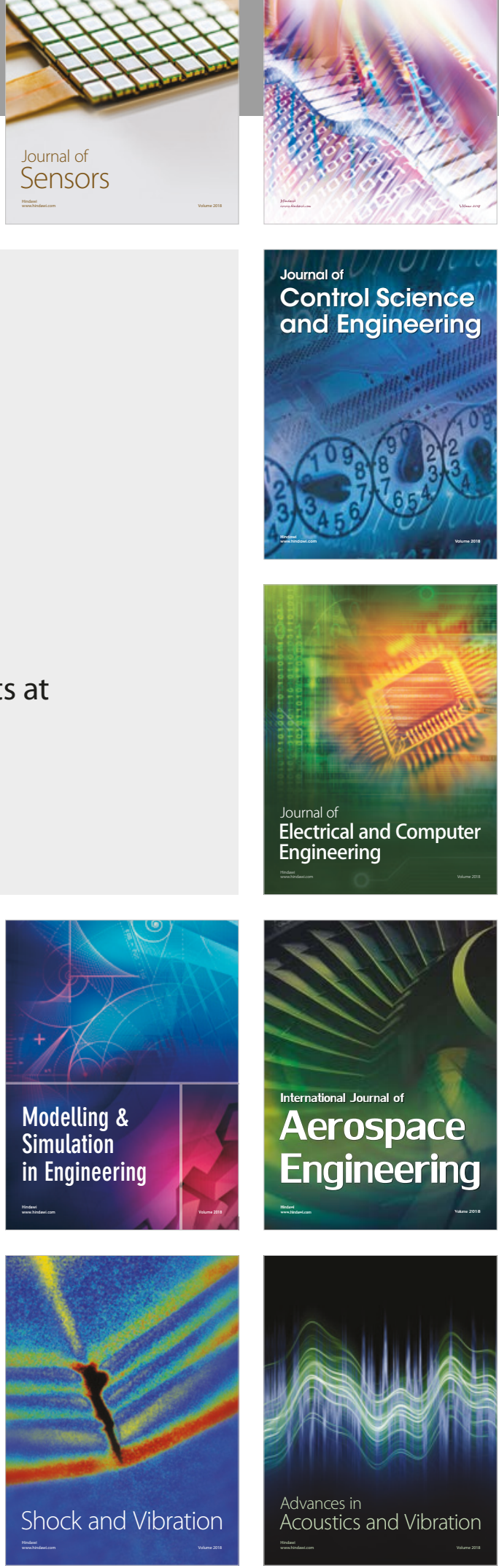